\title{
BORROWING CONSTRAINTS, THE COST OF PRECAUTIONARY SAVING AND UNEMPLOYMENT INSURANCE*
}

\author{
Thomas F. Crossley \\ McMaster University
}

\author{
Hamish W. Low \\ University of Cambridge and \\ Institute for Fiscal Studies
}

January 2005

\begin{abstract}
Job losers exhibit significant heterogeneity in wealth holdings and in the marginal propensity to consume transitory income. We consider potential sources of this heterogeneity, whether (some of) the unemployed face borrowing constraints, and the implications of this heterogeneity for unemployment insurance. We show theoretically how the optimal benefit can depend significantly on borrowing constraints, and on other (nonprecautionary) savings motives. We report empirical evidence that (i) a quarter of job losers cannot borrow for current consumption, (ii) this constraint is binding for a much smaller fraction, and (iii) that "excess sensitivity" is not limited to the constrained.
\end{abstract}

\footnotetext{
*Low (corresponding author): Faculty of Economics, University of Cambridge, Sidgwick Avenue, Cambridge, CB3 9DD, UK, Hamish.Low@econ.cam.ac.uk.

Crossley: Department of Economics, McMaster University, 1280 Main St. West, Hamilton, Ontario, Canada, L8S 4M4, crossle@mcmaster.ca.

For helpful comments we are grateful to numerous colleagues and seminar participants, including participants in the session on Aggegate Implications of Microeconomic Consumption Behaviour at the NBER Summer Institute 2004. The usual caveat applies. For financial support we thank the Social Science Humanities Research Council of Canada, and Trinity College, Cambridge.
} 


\section{Executive Summary}

The ability to smooth consumption in the face of transitory shocks to income depends on the level of unemployment insurance and the ability to self-insure. The ability to selfinsure will depend on the cost of borrowing (credit market imperfections) and on the cost of (precautionary) saving. The cost of savings depends on the timing of income over the life-cycle and the timing of needs, as well as private and market discount rates. Heterogeneity in any of these factors will translate into heterogeneity in the cost of self-insurance.

In this paper, we show theoretically how the value of unemployment benefit can depend significantly on the cost of self-insurance and in particular, on borrowing constraints and on other (non-precautionary) savings motives. In the presence of borrowing constraints, unemployment insurance may have a benefit that derives from smoothing consumption over time after job loss in addition to the benefit of smoothing over states.

We use a Canadian survey to investigate empirically holdings of liquid assets, credit market access, and consumption growth among recent job losers. Job losers exhibit significant differences in wealth holdings at the time of job loss and in the marginal propensity to consume transitory income. We consider potential sources of this heterogeneity and whether (some of) the unemployed face borrowing constraints. We find that (i) a quarter of job losers cannot borrow for current consumption, (ii) this constraint is binding for a much smaller fraction, and (iii) that "excess sensitivity" is not limited to the constrained. 


\section{Introduction}

A literature has emerged recently that studies the ability of households to smooth consumption in the face of transitory fluctuations in income, particularly those fluctuations that result from unemployment. This empirical literature speaks to the cost of business cycles (and the incidence of those costs). It also speaks to the consumption smoothing benefits of unemployment insurance and hence to the optimal level of provision of such public insurance. In our reading, the striking feature of this literature is that job losers exhibit significant heterogeneity in wealth holdings and in the marginal propensity to consume out of transitory income. In this paper, we consider potential sources of this heterogeneity, whether (some of) the unemployed face borrowing constraints, and the implications of this heterogeneity for unemployment insurance.

Dynarski and Gruber (1997) show that consumption changes are more highly correlated with income changes among households headed by high school dropouts and high school graduates than among households headed by college graduates, and they find similar differences by wealth quartile. Gruber (2001) analyses wealth data from U.S. Survey of Income and Program Participation and documents enormous heterogeneity in wealth holdings around job loss. $\mathrm{He}$ reports that the median worker has assets sufficient to finance about two thirds of the income loss from an unemployment spell, but that almost a third of workers cannot finance even $10 \%$ of that income loss. Browning and Crossley (2001) report that while the mean fall in (total) consumption with unemployment in their Canadian data is $14 \%$, a quarter of the job-losing households report no fall in consumption and $10 \%$ of households report that consumption fell by more than half. They also find that the marginal propensity to consume out of unemployment benefit income varies between 0 and .25 for different groups, where the groups are defined by family type and (liquid) wealth. Sullivan (2002) and Bloemen and Stancanelli (2002), using measures of food consumption in U.S. and U.K data respectively, also document significant variation in the marginal propensity to consume out of transitory income across job losers with different wealth levels.

In comparing the behavior of agents with different levels of assets, these studies are following the strategy employed by Zeldes (1989) and Runkle (1991) to study "excess sensitivity" (of consumption to income) in the general population. Those without liquid assets are considered 
to be more likely to be constrained, and the fact that they have a higher marginal propensity to consume out of transitory income is taken to be evidence of borrowing constraints (Dynarski and Gruber, 1997; Browning and Crossley, 2001; Sullivan, 2002; Bloemen and Stancanelli, 2002).

This empirical heterogeneity - and the credit constraint interpretation it is usually given in this literature - raises a number of important issues. First, the broader literature on consumption and savings has recently emphasized that such "excess sensitivity" need not indicate borrowing constraints if preferences do not take the certainty-equivalent form. Research surveyed by Carroll (2001) emphasizes that a precautionary savings motive leads to concave consumption functions and high marginal propensities to consume out of current income at low wealth levels. Moreover, in splitting samples by wealth levels, the empirical literature on consumption smoothing during unemployment is essentially treating wealth levels at job loss as exogenous. Theoretically, savings should respond to the degree of insurance provided by other sources. Empirical support for this proposition has been provided by Engen and Gruber (2001), who demonstrate that wealth levels respond to the generosity of unemployment insurance.

Second, many models that are used to trade off the consumption smoothing benefits of unemployment insurance against the moral hazard cost cannot accommodate either the heterogeneity in wealth levels at job loss or the heterogeneity in marginal propensity to consume that is apparent in the data. In addition, some do not allow a role for borrowing constraints. For example, the canonical model of optimal unemployment benefits with savings is the two period model of Bailey (1978). Because of its transparency and useful insights, the Bailey model is still used to assess empirical estimates of the costs and benefits of unemployment insurance (see for example Gruber, 1997, and Chetty, 2004). However, as we discuss below, the only reasonable interpretation of the structure of the Bailey model is that the unemployed have complete access to credit markets. In addition, because agents in the Bailey model have a single savings motive (precautionary saving against the probability of job loss between the two periods) it is difficult to see how one might relate the Bailey model to the substantial heterogeneity in wealth levels apparent in the data. As we discuss below, recent papers suffer 
similar limitations.

From the point of view of an individual worker, the value of unemployment insurance will depend on how difficult it is to self-insure. This in turn will depend on the cost of borrowing (credit market imperfections) and on the cost of (precautionary) saving. Lentz (2003) has recently emphasized that optimal benefit rates are sensitive to the rate of return on savings. A high rate of return makes it attractive to hold wealth and hence self-insurance is not costly. However, the cost of savings depends not only on market rates of return but also on current needs and the timing of income, as well as rates of time preference. Heterogeneity in any of these factors will translate into heterogeneity in the cost of saving. Market imperfections mean heterogeneity in the cost of saving passes through to heterogeneity in the value of unemployment insurance. Thus the empirical heterogeneity which the literature has documented may indicate substantial heterogeneity in the value of unemployment insurance, and this should be taken into account in an assessment of optimal benefits.

In this paper we explore these issues in two ways. First, we construct a transparent (finite horizon) life-cycle consumption model, extending Bailey (1978). In our model, job loss is exogenous, the unemployed can invest in subsequent earnings capacity, insurance is partly from public unemployment insurance and partly from private savings. Crucially, we introduce (i) a retirement savings motive, (ii) variation in the timing of job loss, and (iii), the possibility of (exogenous) borrowing constraints. We use this model to illustrate the connections between credit market imperfections, the cost of precautionary saving and the role of unemployment insurance. We are able to show theoretically that in the presence of borrowing constraints, unemployment insurance may have a benefit that derives from smoothing consumption over time, in addition to the benefit in the Bailey model (the latter derives entirely from smoothing over states). As one might expect, this additional potential benefit can raise the optimal replacement rate. Having a second savings motive (retirement) provides a starting point for thinking about how the wealth heterogeneity in the data might arise. When the retirement savings motive is strong, self-insurance is less costly because retirement savings can serve double duty - they can also serve as a buffer stock to smooth consumption. In our model, optimal replacement rates vary substantially with the strength of the retirement saving motive 
and age at job loss (from less than 20 percent to almost 60 percent) .

Motivated both by the issues raised above, and by our model, we then use an unusual Canadian survey to investigate empirically holdings of liquid assets, credit market access, and consumption growth among recent job losers. The survey is of individuals who lost their jobs in particular windows in time and collects a broad range of information. Unlike surveys that interview a population sample at regular intervals (like the Panel Survey of Income Dynamics or Survey of Income and Program Participation), our survey collects data on financial circumstances and consumption just prior to job loss as well as at intervals after job loss. To assess the importance of borrowing constraints, we have a unique combination of questions including subjective questions about whether individuals are able to borrow and want to borrow, as well as objective questions on their success at obtaining credit since job loss. The latter are similar to questions in the U.S. Survey of Consumer Finances which have been analyzed by Jappelli (1990) (for the general population). Jappelli et al. (1998) used data from the Survey of Consumer Finances and a two-sample instrumental variables procedure to impute the ability to borrow to households in the Panel Survey on Income Dynamics. In contrast, we have information on the ability to borrow and on consumption growth for the same households.

With respect to liquid assets held at job loss we, like Gruber (2001), find striking heterogeneity. Almost half of job losers reported that their households had no such resources at the time of job loss. A quarter reported that their household had liquid savings of more than three months of usual household income. An innovation of the current paper is to emphasize that a significant part of this variation can be understood in terms of life-cycle considerations. We show that liquid asset holdings rise with age, and at every age are lower for households with children present (high needs). Among older households, those with illiquid pension wealth hold less liquid wealth with which they could smooth a temporary income loss.

Turning to borrowing constraints and consumption growth, a quarter of job losers report that they could not borrow to raise current consumption. A smaller fraction report that this constraint is binding. The incidence of binding borrowing constraints falls with age. Those who report a binding borrowing constraint subsequently exhibit very high consumption growth (relative to those who report not being constrained), consistent with an inability to smooth 
consumption over time. However, even those who assert that they could borrow exhibit "excess sensitivity" of consumption growth to lagged income. This is strong evidence that excess sensitivity cannot necessarily be interpreted as evidence of binding borrowing constraints.

In the next section we develop our model. Section III outlines the implications of our model for consumption smoothing, asset accumulation, and optimal levels of unemployment benefit. Section IV describes the data. Section V presents our empirical analysis of liquid asset holdings, borrowing constraints, and consumption growth. Section VI concludes.

\section{Life-Cycle Model}

Our model might best be thought of as an extension of the Bailey framework. Bailey (1978) models the trade-off between consumption smoothing and moral hazard in a partial equilibrium framework. ${ }^{1}$ In Bailey's two period model, agents may lose their job between the first and second period. They then choose what portion of the second period to spend out of work. Crucially, utility depends only on total income in the second period: the fact that income may be low while out of work is immaterial. This is consistent with the unemployed having complete access to credit markets. However, it is inconsistent with the idea that the unemployed face borrowing constraints and may be in temporarily difficult financial circumstances.

We develop that framework as follows. First, we make time continuous in order to introduce a role for borrowing constraints and to vary the age of job loss. Second, we introduce a retirement savings motive. The latter allows us to vary the cost of holding assets for precautionary reasons. Our model is partial equilibrium but closed with a government budget constraint, like the Bailey model. ${ }^{2}$

There are a number of alternatives to the finite horizon life-cycle model we develop. Hansen and Imrohorglu (1992) model unemployment insurance in an infinite horizon, calibrated dy-

\footnotetext{
${ }^{1}$ The most common framework for thinking about the moral hazard induced by unemployment insurance is search models. In these search models agents typically income maximize, and this is justified by assuming either linear utility (risk neutrality) or perfect insurance. Thus such models preclude consumption smoothing benefits.

${ }^{2}$ We believe that because wealth distributions are so highly skewed, and capital markets open, it is reasonable to model users of unemployment insurance systems as price takers in capital markets. A second potential general equilibrium effect is the effect of unemployment insurance on the vacancy posting behaviour of firms (firms' vacancy decisions do not take into account the positive externality on other firms of creating a "thicker" market). Similarly, we do not capture the negative externality of search on the probability of other people finding jobs. These general equilibrium and externality effects may be important but are beyond the scope of this paper.
} 
namic general equilibrium model. This is less suitable for our purposes of understanding the effects of heterogeneity in the cost of saving because with an infinite horizon, agents must be impatient in order to keep the problem bounded. In an infinite horizon, partial equilibrium model, Lentz (2003) varies the interest rate and illustrates that the value of unemployment insurance depends on the cost of saving. The lower the interest rate, the more costly it is for them to hold a buffer stock of savings, and the more valuable social insurance becomes. However, the infinite horizon framework precludes Lentz from considering patient agents and from explicitly introducing life-cycle considerations. Rendon (2003) carries out a similar exercise in a finite horizon, allowing for some life-cycle effects. His focus is on estimating structural parameters rather than on exploring heterogeneity due to life-cycle effects. Costain (1999) also works with a finite horizon model, but allowing for general equilibrium effects. His focus is on the value of unemployment insurance using a model calibrated to median wealth holdings and so he explicitly ignores the heterogeneity in the data. Further, like Rendon, he does not consider that heterogeneity in characteristics and in wealth may make the value of unemployment insurance very different for different individuals.

\section{A Framework and notation}

Life has three stages: youth, middle-age and old age. We use subscripts to denote the lifestage and note that life-stages may be of different lengths. Agents are risk-averse and maximize expected utility. They begin the first stage (which lasts from 0 until $T_{1}$ ) with initial assets $A_{0}(=0)$. In this stage agents work for a wage, $w_{1}$, and consume continuously. Individuals pay two (proportional) taxes: a pension contribution $\left(\tau^{r}\right)$, and an unemployment insurance contribution $\left(\tau^{u}\right)$. If they choose to consume less than their net income, they accumulate assets. As in Bailey (1978), at the end of the first stage individuals face an exogenous probability $(\pi)$ of job displacement. Where necessary, we use superscripts ${ }^{d}$ (displaced) and ${ }^{n}$ (not displaced) to denote states of the world.

In the second stage (from $T_{1}$ to $T_{2}$ ) agents consume (and save or possibly borrow). If they are not displaced at the end of the first stage, they continue to earn the wage $w_{1}$. If agents are displaced at the end of the first stage, they can return to work immediately at 
some wage which is strictly less than the wage in the job from which they were displaced $\left(w_{2}(I=0)<w_{1}\right)$. Alternatively, they may choose to invest for time $I \leq T_{2}-T_{1}$. During this investment period they receive a benefit determined by the replacement rate $b$. If $I<T_{2}-T_{1}$ they return to work at $T_{1}+I$, earning a wage $w_{2}(I)$ which is increasing in the duration of investment $\left(w_{2}(0) \leq w_{2}(I) \leq w_{1}\right)$. Individuals pay only retirement taxes on unemployment benefits.

We can interpret investment in a number of alternative ways: first, investment may be search with recall (of previous offers) with longer search leading to a better match ${ }^{3}$ second, $^{2}$ investment may be retraining by the unemployed with wages being higher the longer the training period; third, investment may merely be waiting to be recalled (from temporary layoff) to a job with a high wage (relative to the outside option); finally, if we reinterpret unemployment benefit as a minimum payment to the worker, investment may be thought of as on-the-job training where workers receive a minimum payment during the training period, but a higher wage on completion. The presence of unemployment benefit may distort these investment decisions. ${ }^{4}$

In the final stage of life (from $T_{2}$ to $T_{3}$ ), individuals are (exogenously) retired and collect a pension, which they consume. The size of their pension is determined solely by their contributions in the first two stages of life and contains no redistributive element. In retirement individuals pay no taxes. At the end of the third stage they die with terminal assets $A_{3}=0$. The amount of resources available for consumption in retirement is determined by pension wealth plus liquid asset holdings not consumed in earlier stages.

In a general intertemporal consumption model, patience (broadly defined as the inclination to save) will be determined by the interest rate, the rate of time preference, the time path of needs, and the time path of income. All may contribute to heterogeneity in patience. For example, recent studies of household wealth (Samwick, 1998) and consumption growth (Alan and Browning, 2003) provide empirical support of heterogeneity in the rate of time preference.

\footnotetext{
${ }^{3}$ It is possible that wages decline if unemployment is too long. In the current model, there is no uncertainty about job offer arrival, and so if there were no unemployment benefit, we would be able to ignore the part of the investment schedule which is declining.

${ }^{4}$ In the Bailey model, moral hazard arises due to the utility of leisure in the second stage. We model moral hazard as arising through the investment decision to allow the possibility that search during unemployment is productive.
} 
Attanasio et al. (1999) show empirically that children make households act as if they are more impatient. Nevertheless, for transparency, we choose to model only one determinant of the agents' inclination to save. We assume that there is no discounting or rate of return $(\delta=r=0)$. We also abstract from modelling explicitly changes in needs. This gives us flat desired consumption paths. However, we can vary impatience (again, defined as the inclination to save) in this model by varying the growth rate of income.

In our model we alter the growth rate of income through (exogenous) changes to the pension system. With high withholding (large $\tau^{r}$ ) agents face a rising income profile. Such agents would like to borrow, and saving is costly for such agents. With low withholding, agents face a falling income profile and wish to save. This is crucial because it will allow us to explore the value of unemployment insurance to agents for whom it is more or less costly to hold savings.

Savings motives are not additive: liquid assets held for precautionary reasons (smoothing consumption in the face of a temporary income loss) can be consumed in retirement if the negative shock is not realised. Equally, liquid assets held for retirement purposes may be partially used for precautionary reasons if unexpected shocks occur. This point is also emphasized by Dynan, Skinner and Zeldes (2002) who argue that precautionary savings and savings for a bequest motive cannot be distinguished. It is more costly for an impatient agent to accumulate precautionary balances as the marginal utility of current consumption is high (and similarly, resources that become available late in life - if the shock is not realized - have low value).

We consider an extreme variation in the cost of borrowing, comparing cases where agents can borrow freely (subject only to the terminal asset condition) with cases where they face an exogenous borrowing limit $A_{t} \geq-\phi$.

Notation in the model is summarized in Table 1 and timing in Figure 1.

\section{B Individual Optimization Problem}

We now lay out the individual optimization problem, taking $b, \tau^{r}$, and $\tau^{u}$ as given. The individual maximises

$$
V_{1}=\max _{c_{t}, A_{1}} \int_{0}^{T_{1}} u\left(c_{t}\right) d t+\pi V_{2}^{d}\left(A_{1}\right)+(1-\pi) V_{2}^{n}\left(A_{1}\right)
$$


subject to the budget constraint

$$
\int_{0}^{T_{1}} c_{t} d t=-A_{1}+Y_{1}\left(1-\tau^{r}-\tau^{u}\right)
$$

and, if present, the credit constraint,

$$
A_{1} \geq-\phi
$$

The solution to this problem can be characterised by the Euler equation:

$$
\begin{aligned}
\frac{\partial V_{1}}{\partial A_{1}} & =u^{\prime}\left(c_{1}\right)-\pi \frac{\partial V_{2}^{d}}{\partial A_{1}}-(1-\pi) \frac{\partial V_{2}^{n}}{\partial A_{1}}+\mu_{1}=0 \\
\mu_{1} & \geq 0, \quad A_{1} \geq-\phi .
\end{aligned}
$$

The presence of the credit constraint affects equation (2) in two possible ways: first, it may cause the Euler equation to be violated (ie. $\mu_{1}$ is strictly positive); second, the constraint may bind in period 2 and so can affect behaviour in period 1 through either $\frac{\partial V_{2}^{d}}{\partial A_{1}}$ or $\frac{\partial V_{2}^{n}}{\partial A_{1}}$, even though $\mu_{1}=0$.

In the absence of credit constraints, the solution is simple because the consumption path post-displacement can be separated from the timing of income: individuals displaced in the second stage choose investment simply to maximise income, ${ }^{5}$

$$
\max _{I} w_{2}(I)\left(T_{2}-T_{1}-I\right)\left(1-\tau^{u}-\tau^{r}\right)+b Y_{1} I\left(1-\tau^{r}\right)
$$

This yields the first order condition

$$
w_{2}^{\prime}(I)\left(T_{2}-T_{1}-I\right)\left(1-\tau^{u}-\tau^{r}\right)+b Y_{1}\left(1-\tau^{r}\right)=w_{2}(I)\left(1-\tau^{u}-\tau^{r}\right)
$$

where the left hand side is the marginal benefit of investment and the right hand side is the marginal cost of investment, analogous to the partial equilibrium, linear utility model (Mortensen, 1986). The marginal benefit of investment is increased by the unemployment benefit paid and so a positive replacement rate induces inefficient (over) investment.

This level of investment determines income post-displacement. Since there is no discounting, individuals choose consumption to be constant in any particular state. Once we know

\footnotetext{
${ }^{5}$ Noting that the pension tax paid in stage 2 is returned in stage 3 .
} 
income and hence consumption post-displacement as a function of $A_{1}$, we can solve for assets held at the end of period 1 by using the envelope theorem to replace $\frac{\partial V_{2}^{n}}{\partial A_{1}}$ and $\frac{\partial V_{2}^{d}}{\partial A_{1}}$ in equation (2) by the marginal utility of consumption in each state.

The presence of credit constraints introduces an interaction between the investment decision and the consumption decision because, if the constraint binds, longer investment means a longer period at lower consumption levels. The choice of investment depends on the consumption level in the investment period and this in turn means investment will depend on asset holdings, $A_{1}$. To solve the problem with the credit constraint, we have to solve simultaneously the asset allocation equation (2) and for optimal investment (equation (8) below).

After displacement, the individual chooses the length of investment and the amount of consumption to solve

$$
V_{2 I}^{d}\left(A_{1}\right)=\max _{c_{t I}, A_{1+I}, I} \int_{T_{1}}^{T_{1+I}} u\left(c_{t I}\right) d t+V_{2 E}^{d}\left(A_{1+I}, I\right)
$$

subject to

$$
\begin{aligned}
\int_{T_{1}}^{T_{1+I}} c_{t I} d t & =A_{1}-A_{1+I}+b Y_{1} I\left(1-\tau^{r}\right) \\
A_{1+I} & \geq-\phi
\end{aligned}
$$

where $V_{2 E}^{d}\left(A_{1+I}, I\right)$ is the value from reemployment after investment $I$ with remaining assets $A_{1+I}$. This recursive structure of the problem means we can solve (5) using Lagrange multipliers from future periods, recognising that the credit constraint may bind after reemployment if impatience is high enough (see appendix).

To determine investment, we need to use the first-order condition from maximising equation (5) with respect to $I$.

$$
\frac{\partial V_{2 I}^{d}}{\partial I}=0=\frac{\partial V_{2 E}^{d}}{\partial I}+u\left(c_{2 I}\right)+\lambda_{2 I} b Y_{1}\left(1-\tau^{r}\right)-\lambda_{2 I} c_{2 I}
$$

where $\partial V_{2 E}^{d} / \partial I$ is the marginal benefit of further investment realised once reemployed and $\lambda_{2 I}$ is the Lagrange multiplier on the budget constraint in the investment stage in period 2, 
equation (6). Using the solution for $\partial V_{2 E}^{d} / \partial I$ derived in the appendix, and rearranging,

$$
\begin{gathered}
w^{\prime}(I)\left(T_{2}-T_{1}-I\right)\left[\lambda_{2 E}\left(1-\tau^{r}-\tau^{u}\right)+\lambda_{3} \tau^{r}\right]+b Y_{1}\left[\lambda_{2 I}\left(1-\tau^{r}\right)+\lambda_{3} \tau^{r}\right] \\
=w(I)\left[\lambda_{2 E}\left(1-\tau^{r}-\tau^{u}\right)+\lambda_{3} \tau^{r}\right]+\Psi
\end{gathered}
$$

The left hand side of equation (8) is the marginal benefit of investment and the right hand side is the marginal cost of investment, analogous to condition (4). The marginal benefit of investment includes unemployment benefit and the resulting increase in the future wage. Here (and in contrast to condition 4) both are weighted by marginal utility terms which are share weighted averages of the marginal utilities in the stages in which the relevant resources will be realized.

The first term in the marginal cost is the (forgone) wage, again valued at a share weighted average of the marginal utilities in the periods in which it is received (note that because of the mandatory pension contributions, a fraction of current earnings is received in retirement). The second term $\Psi$ can be approximated by

$$
\Psi \approx \gamma \Delta c_{2 E} u^{\prime}\left(c_{2 E}\right)
$$

where $\gamma$ is the coefficient of relative risk aversion which captures the degree of aversion to fluctuations in consumption. The term $\Psi$ is a utility cost term associated with the failure to smooth consumption between the investment and earnings substages of period $2 .{ }^{6}$ The presence of $\Psi$ increases the marginal cost of investment because consumption is no longer smoothed over substages in a way that would have occurred if there had been no credit constraints. The size of this cost is increasing in the degree of fluctuation aversion and would be zero if utility were linear. This reduces investment below the level of investment that would occur if unconstrained. Investment when constrained may potentially fall below the level which would maximise earned income. In this case, increasing unemployment benefits can induce a more efficient level of search.

For given values of $\tau^{r}, \tau^{u}$ and $b$, we can now solve for $A_{1}$ and $I$ using equations (2) and (4) if unconstrained, or equations (2) and (8) if constrained. We solve for $\tau^{u}$ to balance the budget as discussed in the next subsection.

\footnotetext{
(4).

${ }^{6}$ If the credit constraint is not binding, $\Psi=0$ and $\lambda_{2 I}=\lambda_{2 E}=\lambda_{3}$ and so equation (8) reduces to equation
} 


\section{Government Budget Constraints}

Unemployment benefit is financed in our model by the $\operatorname{tax} \tau^{u}$ and we set $\tau^{u}$ to balance the government budget constraint. Ignoring the government budget constraint would mean increases in unemployment duration associated with more generous benefits do not introduce extra costs.

The budget constraint for the unemployment insurance system is:

$$
\tau^{u}\left(w_{1} T_{1}+\pi w_{2}\left(I^{*}\right)\left(\left(T_{2}-T_{1}\right)-I^{*}\right)+(1-\pi) w_{2}\left(T_{2}-T_{1}\right)\right)=\pi I^{*} b Y
$$

This implies that the budget is set to balance across individuals and there is redistribution from workers to the unemployed. Because there is no aggregate risk, we can alternatively say that the budget balances in expectation and so insurance is actuarially fair.

Budget balance in the pension system is imposed by each individual receiving the sum of their earlier contributions as retirement income: $Y_{3}=\tau^{r}\left(Y_{1}+Y_{2}(I)\right)$. This implies that the pension system contains no element of redistribution between individuals and no notion of insurance. $^{7}$

\section{Implications of the Model}

In this section, we use our model to show the implications of the cost of saving, borrowing constraints and unemployment insurance for individual saving, consumption smoothing and investment behaviour. We then use these implications to derive optimal benefit levels which vary with the cost of saving and borrowing. Implications of the model are demonstrated partly analytically and partly numerically.

For the numerical analysis we assume CRRA utility,

$$
u\left(c_{t}\right)=\frac{c_{t}^{1-\gamma}}{1-\gamma}
$$

and a simple investment function, $w(I)=I^{\eta}$. Parameters used are summarised in Table 2 . We explore variation in replacement rates, variation in the timing of layoff and variation in the

\footnotetext{
${ }^{7}$ If there were only one government budget constraint, pension provision could contain an element of redistribution by providing "pension credits" for periods in unemployment. Similarly we do not consider redistribution across individuals who face different job loss risk, $\pi$, or different loss of potential earnings. Our focus is the on the non-redistributive aspects of unemployment insurance.
} 
patience of agents. As noted above, the latter is controlled by the pension $\operatorname{tax}\left(\tau^{r}\right)$ which controls the growth rate of expected income. With low $\tau^{r}$ agents anticipate low income in the future and save; with high $\tau^{r}$ agents anticipate high income in the future and would like to borrow.

\section{A Consumption and Saving}

From the first-order conditions of the individual optimisation problem, in the absence of borrowing constraints, or if the constraints do not bind, marginal utility is smoothed over time (at least in expectation):

$$
\begin{gathered}
\lambda_{1}=\pi \lambda_{2 d}+(1-\pi) \lambda_{2 n} \\
\lambda_{2 I}=\lambda_{2 E}=\lambda_{2 d}=\lambda_{3 d} \\
\lambda_{2 n}=\lambda_{3 n}
\end{gathered}
$$

but not smoothed over states:

$$
\lambda_{2 n} \neq \lambda_{2 d}
$$

The finiteness of life means that households cannot perfectly self-insure even in the absence of borrowing constraints. Unemployment insurance has what we term an "insurance benefit", in that it helps to smooth marginal utility across states, reducing $\lambda_{2 d}-\lambda_{2 n}$ which is the "permanent shock" of job loss (See also Browning and Crossley, 2001). This is the benefit of unemployment insurance that operates in the Bailey model.

If credit constraints bind, then from the first-order conditions,

$$
\begin{gathered}
\lambda_{1}=\pi \lambda_{2 I}+(1-\pi) \lambda_{2 n}+\mu_{1} \\
\lambda_{2 I}=\lambda_{2 E}+\mu_{2 I}=\lambda_{3 d}+\mu_{2 I}+\mu_{2 E} \\
\lambda_{2 n}=\lambda_{3 n}+\mu_{2 n}
\end{gathered}
$$

Marginal utility is again only partially smoothed over states $\left(\lambda_{2 d} \neq \lambda_{2 n}\right)$, but in addition, marginal utility is only partially smoothed over time after job loss $\left(\lambda_{2 I} \neq \lambda_{2 E} \neq \lambda_{3 d}\right)$. By reducing $\lambda_{2 I}-\lambda_{2 E}$ unemployment insurance can have another benefit (beyond the insurance benefit noted above): it helps to smooth consumption over time. This consumption smoothing benefit 
of unemployment insurance is absent in the Bailey (1978) model because post-displacement, consumption is independent of labour market state.

Figure 2 displays the time paths of assets and consumption for simulations of our model with different parameter values. The left hand side panel present time paths for agents who are able to borrow; the right hand side panels present time paths for agents who are unable to borrow. Moving from top to bottom the panels are differentiated by a decreasing cost of saving. In the top panels a very high value for pension withholdings is chosen which has the effect of making additional savings costly and agents very impatient (they would like to bring resources forward from the future.) In the bottom panels illiquid pension contributions are very low, the income profile is downward sloping, agents have a strong life-cyle (retirement) savings motive, and hence are patient. The middle panels present an intermediate case.

When agents are able to borrow, consumption is equalized across time (after the shock is realised) and the consumption path is independent of the timing of income. However, because time diversification is limited by the finiteness of life, consumption is not completely equalized across states. Patient agents (row iii in Figure 2) smooth by saving and their holdings of liquid assets increase with age until retirement, while impatient agents (row $i$ ) smooth by borrowing and their borrowing increases with age until retirement. This implies that as the cost of saving increases, individuals save less, and then borrow if the cost of saving becomes high enough.

The right hand column of Figure 2 shows that a similar results holds when individuals are unable to borrow: as the cost of saving increases, individuals save less, and then want to borrow if the cost of saving becomes high enough. Because patient agents have sufficient liquid wealth to smooth without borrowing, their time paths of consumption are unaffected by their inability to borrow (row iii). By contrast, impatient agents who cannot borrow do not fully smooth consumption across time after job loss and consumption rises at reemployment (rows $i$ and $i i)$.

\section{B Effects of Varying the Replacement Rate}

We show the effects of varying the replacement rate on savings, consumption loss on unemployment and investment behaviour. 
Saving Figure 3 shows the extent of asset accumulation $\left(A_{1}\right)$ for different replacement rates and for different costs of saving and borrowing. Figure 4 shows corresponding saving rates. For both figures, each row represents a different cost of saving, and in each panel we show the case where agents are able to borrow and the case where agents are unable to borrow. The two columns in each figure represent different ages when job loss may occur.

Figure 3 reinforces that the extent of liquid asset holdings and the ability to self-insure depends on the cost of saving: greater forced retirement saving or greater impatience lead to lower liquid asset holdings. This result holds whether or not individuals are able to borrow. However, Figure 3 shows that the inability to borrow leads to greater asset holdings relative to the case where individuals are able to borrow. Further, row (ii) in Figure 3 shows that borrowing constraints can lead to greater asset holdings even if asset holdings are positive in the unconstrained case.

Asset accumulation in this model is for partly for precautionary reasons and partly to fund consumption in retirement. Assets not needed for precautionary reasons can instead be consumed in retirement. In this context, an increase in unemployment insurance will crowd out liquid asset holdings, ${ }^{8}$ but the extent of the crowd-out will depend on the substitutability between asset motives: crowd-out is greater when liquid assets are not used for consumption in retirement (row $i$ in Figure 3).

Figure 3 and 4 show the effect of earlier job loss. Figure 3 shows that asset holdings at job loss do not differ significantly with age of job loss for the baseline and very impatient cases. This similar level of asset holdings means a greater savings rate (Figure 4) when job loss is earlier in life. For patient individuals, the credit constraint the savings rate does not vary with age of job loss. Finally, when job loss is earlier, the crowding out effect of the replacement rate on the savings rate is more marked.

Consumption Loss In Figure 5 simulations of the model are used to generate plots of $\Delta \ln c_{t}$ against the unemployment replacement rate for agents that differ by patience, age at job loss and access to credit markets. In all cases, consumption loss decreases as benefits increase, but among the impatient (row $i$ ) and intermediate agents (row $i i$ ) the loss is greater

\footnotetext{
${ }^{8}$ Engen and Gruber (2001) estimate the extent unemployment insurance crowds out precautionary saving.
} 
and the relationship is steeper when borrowing is restricted. In other words, unemployment is more costly and unemployment benefit provides more insurance when saving and borrowing are costly. Self-insurance is also harder against job loss early in life and Figure 5 shows that consumption loss is greater for job losses earlier in life. ${ }^{9}$

Investment Equation (8) in section B shows how the return to investment depends on the presence of borrowing constraints. This is illustrated by the simulations presented in Figure 6. Each panel plots the duration of investment against the replacement rates. The six panels differ by the assumed patience of the agent and by the timing of job loss. Among the impatient agents and agents of intermediate patience, borrowing constraints lead to under-investment, and efficient search durations are induced by positive replacement rates. This is particularly the case when job loss happens earlier in life. As we saw in the preceding analysis of consumption smoothing, the very patient agents are unaffected by borrowing constraints (because they have considerable liquid savings). As with consumption, heterogeneity in impatience only matters for search behaviour if individuals are unable to borrow.

\section{Optimal Benefits}

We have shown that the cost of saving and the ability to borrow matter for understanding how individuals behave in response to unemployment insurance. This raises the issue of how optimal unemployment insurance depends on the cost of saving and the ability to borrow. We show the dependence on the ability to borrow analytically ignoring the retirement stage and the retirement tax. We then show the dependence on the cost of saving through numerical calculations of optimal benefits in the complete model varying the retirement tax.

We calculate the marginal benefit of increasing the replacement rate, $\partial V_{1} / \partial b$, from equation (1) and evaluate this at optimal choices for investment and saving by the individual to give

\footnotetext{
${ }^{9}$ Gruber (1997) and Browning and Crossley (2001) both estimate regression equations of the form:

$$
\Delta \ln c_{t}=X \beta+\alpha b+e
$$

where legislative variation (across time, or time and jurisdictions) is used to estimate $\alpha$. Gruber interprets his estimate of $\alpha$ as an estimate of the insurance benefits of unemployment insurance (and uses that estimate in optimal benefit calculations based on the Bailey model). In contrast, Browning and Crossley set out an explicit (Euler equation) framework in which $\alpha$ captures the effect on consumption growth of a binding credit constraint. In terms of the model presented here, Gruber interprets $\alpha$ as $\lambda_{2 d}-\lambda_{2 n}$, while Browning and Crossley interpret $\alpha=\lambda_{2 I}-\lambda_{2 E}=\mu_{I}$.
} 


$$
\frac{\partial V_{1}}{\partial b}=-\lambda_{1} Y_{1} \frac{\partial \tau^{u}}{\partial b}+\pi\left(\lambda_{I} Y_{1} I-\lambda_{E} E_{2}^{d}(I) \frac{\partial \tau^{u}}{\partial b}\right)-(1-\pi) \frac{\partial \tau^{u}}{\partial b} \lambda_{n} Y_{2}^{n}
$$

where $\lambda_{i}=\partial u / \partial c_{i}$ with $i \in\{1, n, I, D\}$ corresponding to stage 1 , the non-displaced stage, the investment stage post job loss and the earnings sub-stage after returning to work, respectively. We use the envelope theorem to ignore indirect effects of changing benefits operating through optimised values of $I, A_{1}, A_{1+I}$.

We set this expression equal to 0 , use the approximation $\lambda_{i} \approx \lambda_{n}-u^{\prime \prime}\left(c_{n}\right)\left(c_{n}-c_{i}\right)$ and rearrange to give

$$
\begin{gathered}
\pi Y_{1} I\left\{1+\gamma\left[\frac{\left(c_{n}-c_{E}\right)}{c_{n}}\right]+\gamma\left[\frac{\left(c_{E}-c_{I}\right)}{c_{n}}\right]\right\} \\
=\frac{\partial \tau^{u}}{\partial b}\left\{(1-\pi) Y_{2}^{n}+\pi E_{2}^{d}(I)\left(1+\gamma \frac{\left(c_{n}-c_{E}\right)}{c_{n}}\right)+Y_{1}\left(1+\gamma \frac{\left(c_{n}-c_{1}\right)}{c_{n}}\right)\right\}
\end{gathered}
$$

The left hand side represents the marginal benefit of an increased replacement rate if job loss occurs. The right hand side represents the marginal costs which arise due to a higher tax rate. Higher taxes impose a cost in the first stage. They also impose a cost throughout the second stage if no job loss occurs and after return to work if job loss occurs. We want to focus, however, on the gross marginal benefit. The marginal benefit depends on the consumption differences in the square brackets: the first is the difference in consumption between the "no job loss" state and the "reemployed" state, the second is the difference in consumption at the time of search and consumption in the future after reemployment. The first of these terms is the benefit of smoothing over states, the second is the benefit of smoothing over time. If there were no credit constraints, this second benefit would be absent because consumption would be smooth after job loss. ${ }^{10}$ Both terms are multiplied by $\gamma$ : this represents the utility cost of consumption not being smooth. With more general utility, the term on the first consumption difference would be risk aversion, whereas the term on the second would be fluctuation aversion.

Put another way, borrowing constraints limit the time diversification of risk. In particular, in our model they prevent the optimal allocation of resources (over time) in the bad state. As

\footnotetext{
${ }^{10}$ This equation is similar to equation (2) in Chetty (2004) except for the benefit of smoothing over time and taxes are paid in the first stage in our model.
} 
a consequence, they exacerbate the difference (in marginal utility) between the two states of the world, and raise the value of the insurance provided by the unemployment benefit system.

In Figure 7 we solve numerically for the optimal replacement rate allowing for the retirement stage and imposing the no borrowing condition. We vary the age at which job loss may occur and we vary the cost of holding savings through varying the retirement tax. The most striking point in the figure is the extent of heterogeneity in optimal replacement rates: the optimal replacement rate varies from 0.17 to 0.59 even without preference heterogeneity in risk aversion.

Further, Figure 7 highlights that the effect of the borrowing constraint depends on the cost of saving: for each age, below a given cutoff value of $\tau^{r}$, the optimal replacement rate is constant and equal to the optimal rate without borrowing constraints. This is because the borrowing constraint is not binding and so varying $\tau^{r}$ affects the path of assets but not the path of consumption or the marginal benefit of unemployment insurance. Above this cutoff value of $\tau^{r}$, the optimal replacement rate varies but the relationship is not monotone: as impatience increases, the optimal benefit increases (because holding buffer stock saving is more costly) but if impatience becomes high enough, individuals become unwilling even to pay the insurance premium in stage 1. Alternatively, we can interpret the effect of increasing $\tau^{r}$ as showing that unemployment insurance has more value for agents who have made substantial pension contribution, and hence do not wish to save; but has less value for agents who are privately saving for retirement and hence have a buffer stock.

The optimal replacement rate declines with age at job loss. This is partly because the impact of the shock to lifetime income is less if job loss occurs later in life, partly because the cost of accumulating saving for self-insurance is less and partly because the moral hazard effect is smaller.

A final implication in considering the value of unemployment insurance is that for some parameterisations (for example with $\tau^{r}=0.3$ ) credit constraints can raise welfare. The reason is that the displaced agent does not internalize the negative externality that her search behaviour has through the government budget constraint. Since the borrowing constraint reduces search, it mitigates the moral hazard cost of unemployment insurance and leaves the government able to offer more insurance. Another way to think about this is that in a second best world, the 
ability to control borrowing would give the government a second instrument to reduce moral hazard, analogously to the result in Diamond and Mirrlees (1979).

\section{Data, Sample and Institutional Setting}

The empirical analysis in this paper is based on the 1995 Canadian Out of Employment Panel (COEP). The Canadian Out of Employment Panels are a series of surveys commissioned by Human Resources Development Canada for the purposes of evaluating legislative changes to the Canadian unemployment insurance system. The flows of job separations within certain time windows formed the sampling frames for these surveys.

Data from the 1995 survey $^{11}$ contain the detailed questions on the ability and desire to borrow which are central to the empirical work reported in this paper. The respondents in the 1995 survey lost their jobs in the first half of 1995, and were interviewed twice, in the third and fifth quarters after job loss. Thus the respondents were first interviewed in the last quarter of 1995 and first quarter of 1996. Information was collected pertaining to their circumstances at the interview dates and retrospectively about their circumstances prior to the end of the relevant job, and over the intervening period. Information was collected about work, training, and job search, about household composition, consumption, income and finances, and about benefit receipt.

These data offer a number of advantages. First, the data reports on assets and debts, consumption, and borrowing constraints for the same households. So, for example, while Jappelli et al. (1998) are forced to use data from the SCF and a two-sample instrumental variables procedure to impute the ability to borrow to households in the PSID, we can directly examine the consumption growth of households that do and do not report borrowing constraints. Second, the COEP is unusual in collecting a measure of total consumption, not just food. Third, because it is a survey specifically of job losers, the data contain a large sample of unemployed individuals. Fourth, because the COEP survey is designed around the job loss, the timing of information is ideally suited to our purposes. For example, there is information on assets and

\footnotetext{
${ }^{11}$ The survey was conducted by the Special Surveys Division of Statistics Canada, and further details are available at: http://www.statcan.ca/english/IPS/Data/72M0001XCB.htm.
} 
debts at exactly the time of job loss. With a regular panel survey such as the PSID or SIPP, we would have to use information collected at the last interview prior to the beginning of an unemployment spell, and with administrative data, such as that employed by Lentz (2003), information is typically annual. Finally, a number of other data sets suffer from ambiguities with respect to the time period to which information in the data pertains (see, for example, the discussion of the timing of the PSID consumption information in Dynarski and Gruber, 1997). The COEP data do not suffer from such ambiguities.

There are 7818 respondents to the 1995 COEP. The COEP samples job separations of various types, including quits, dismissals, separations due to illness, and temporary and permanent layoffs. In the selection of a sample for analysis, we discard 18 respondents who did not report a separation reason. We also discard 464 individuals who, although they lost a job, reported continuing employment in a second job. Next, we delete from the sample 665 respondents who reported that they quit to take another job. These individuals experienced little or no unemployment and are outside the scope of our interest. Finally we delete 1091 individuals age 25 or younger and 474 individuals over age 55 , to focus on prime age workers.

Of the remaining 5015 observations, we focus on those 2922 who lived in a nuclear family (alone, with a spouse, or spouse and children) and were the primary earner in their household. Past experience with this data suggests that the quality of the survey responses on household finances is lower among respondents in other family types (for example, living with their parents or with unrelated adults.) The job loss of primary earners is of particular interest, and in focusing on primary earners, we are following much of the previous literature (for example, Dynarski and Gruber, 1997). Of these 2922 respondents, 1659 were employed at the time of the first interview. The other 1263 were not working at the time of interview, though some of these had spells of employment between the initial job loss and the interview. The multivariate analyses reported in the paper are based on slightly smaller samples, due to the inevitable item non-response in a large and comprehensive survey.

One way to think about the environment from which respondents are drawn is to consider the income shock associated with job loss. There is information on the change in monthly, take-home household income between the month just prior to the job separation and the month 
prior to the first interview. The mean percentage change for respondents out of work at the first interview is - $22 \%$ (median -20\%). A quarter of out-of-work respondents report income losses in excess of $39 \%$. The modest size of the average income shock associated with non-employment (a complete loss of individual earnings) reflects several factors. The unemployment insurance system in Canada is fairly generous, with statutory replacement rates over $50 \%$ and benefits lasting up to a year. Moreover, because the Canadian income tax system is progressive, the actual (after-tax) replacement rate is often higher than the statutory rate. Against that, insurable earnings are capped, and workers losing jobs with earnings above the maximum insurable earnings will have an effective replacement rate below the statutory rate. Both eligibility for benefits and the duration of benefits depend on the extent of recent employment. However, Canada also has a second tier of income support: a means-tested social assistance program that would be available to those who are ineligible for benefits, or whose benefits expire. Finally, while we focus on the primary earners, these workers live in households, and many of those households have other earners. Quite mechanically, if a worker provides $50 \%$ of household income prior to job loss, and faces a $60 \%$ actual replacement rate, then the job loss represents a shock to personal income of $-40 \%$ but to household income it is a shock of $-20 \%$. In addition, there may be labour supply responses among other earners in the household.

\section{Empirical Analysis}

Our model illustrates that borrowing constraints, as well as variation in the cost of saving due to life-cycle events and the timing of income, are important determinants of the impact and value of unemployment insurance. We now examine whether these factors are empirically important. In particular, we use the 1995 COEP data to relate liquid asset holding at job loss to life-cycle events and the timing of income, to investigate borrowing constraints after job loss, and to relate consumption growth after job loss to those constraints.

\section{A Liquid Assets at Job Loss}

The COEP data collects information about liquid assets with the following questions:

- Do you or someone in your household have any assets that YOU could draw on if it was really necessary? For example, money in the bank, savings bonds or RRSPs that 
are cashable, or insurance policies, etc. Please do not include fixed assets such as house, cars, boats, etc.

- Roughly how much do you have available in such assets?

The respondent is then asked how these quantities have changed since the date of the job loss. This was followed by similar questions about debt:

- Apart from cars or mortgage, do you and your household have any other debts? Please think of all sources such as loans and credit cards.

- Roughly how much debt apart from cars or mortgage do you have?

Again the level at interview and the change since job loss were collected, allowing us to calculate the level at job loss.

Figure 8 presents the empirical cumulative distributions of liquid assets (top left), unsecured debt (top right) and net position (assets - debt, bottom left). All refer to the time of job loss, and are measured in months of usual household income. The first point to note is that almost half of job losers reported that their households had no such resources at the time of job loss. The second striking feature of Figure 8 is the heterogeneity in liquid assets at job loss. A quarter of our sample reported that their household had liquid savings of more than three months of usual household income. The empirical cumulative distributions debt and for net positions have similar features: many zeros and striking heterogeneity. This heterogeneity in financial circumstances echoes that documented by Gruber (2001) using the U.S. Survey of Income and Program Participation.

The bottom right panel of Figure 8 shows, by age, the fraction of our sample who hold at job loss (i) liquid assets amounting to at least one month of usual household income, (ii) unsecured debt of at least one month of usual household income, (iii) both, (iv) neither. The fraction having only debt falls with age, while the fraction having only assets rises. At all ages a nontrivial fraction hold both liquid assets and unsecured debt.

The next step in our analysis is to consider whether some of the observed heterogeneity in liquid assets can be understood in terms of life-cycle considerations. As we have emphasized above, holding liquid wealth is more costly if current income is low, or future income is expected to be high. One important determinant of the timing of income is retirement provision. All 
Canadian workers participate in a public pension scheme (either the Canada Pension Plan or the Quebec Pension Plan). However, this is only one component of retirement provision in Canada. Workers have, of course, their own savings, and in addition many Canadians participate in (registered) pension plans through their employer. These pension plans are a form of illiquid wealth. All else equal, it is more costly for workers with such plans to hold a buffer of liquid assets, because contributions to these plans mean that their current disposable income is lower, and the payout of the plan means that resources on retirement will have lower marginal value. In our sample, $38 \%$ report being covered by an employer administered pension in the job that ended. A second life-cycle consideration is that it is more costly to hold a buffer of liquid assets when needs are high (the current marginal utility of income of is high.) Needs are high when children are present in the household. As Attanasio et al. (1999) emphasize, demographic effects in intertemporal allocation operate very much like variations in private discount rates.

Figure 9 presents age profiles of financial circumstances for workers losing jobs with and without an employer sponsored pension (top panels) and with and without children present in the home (bottom panels). The left hand panels present liquid assets at job loss (measured in months of usual household income) while the right hand panel present net position (liquid assets - unsecured debt, again measured in months of usual households income).

The first obvious point about Figure 9 is that both liquid asset holding and net position rise with age. In the top panel of Figure 9 we further see that the for those without employer sponsored pensions, liquid assets rise rapidly after age 45, presumably as these households accumulate retirement savings. ${ }^{12}$ This is not true of workers with employer sponsored pensions, so that after age 45 a difference in liquid asset holdings opens up between the two groups. This is consistent with the idea that there is considerable substitution between personal pension wealth and household savings: as in our model, future income implied by illiquid pension wealth lowers liquid wealth holding. While this cross-sectional evidence is only suggestive, recent studies using pension reforms in Italy and the United Kingdom as natural experiments

\footnotetext{
${ }^{12}$ In matching a life-cycle model with impatience and precautionary savings to the life-cycle consumption profiles, Gourinchas and Parker (2003) estimate that households begin to accumulate substantial retirement savings after age 45. Carroll (1997) finds a somewhat later date.
} 
support this conclusion (Attanasio and Brugiavini, 2003, Attanasio and Rohwedder, 2004.)

In the bottom panels of Figure 9 we see that at every age, households with children currently present (and thus with high current needs) hold smaller stocks of liquid wealth.

Table 3 models the characteristics of those holding assets. The distribution of liquid asset holdings in our data (again, measured as months of usual household income) has two important characteristics: (i) a great many zeros, and (ii) the positives are very skewed. ${ }^{13}$ Our multivariate analysis is therefore based on a "two-part" model (Manning, Duan and Rogers, 1987) in which the probability of positive holdings is modelled with a probit, and the quantity of holdings (conditional on positive holdings) is modelled with a log-linear regression.

The age profile is statistically significant in the quantity (months) of liquid assets (conditional on positive) but not in the probability of having positive assets. Education has significant effects on both the probability of having liquid assets and in quantity of assets conditional on having any. Respondents with spouse present are more likely to have positive assets, and respondents who self-report visible minority status are both less likely to have positive assets and have lower assets conditional on having any at all. The expectation of job loss appears to increase the size of liquid asset holdings conditional on having positive holdings, but has no effect on the probability of having positive holdings. We find no significant gender effects.

The presence of children significantly reduces both the probability of having a buffer of liquid assets and the quantity of assets conditional on positive holdings. Finally, the pensionage interactions are jointly significant in the in the probit (for any assets) but not in the log-linear regression for the amount of holdings, conditional on positive holdings.

\section{B Borrowing Constraints}

It is reasonable to think that recent job losers may be more likely to be credit-constrained than the general population. ${ }^{14}$ Casual empiricism suggests that employment status is a key criteria considered by lenders. Moreover, investments in future earnings (either human capital or job

\footnotetext{
${ }^{13}$ The latter, for example, means that the normality assumption of a Tobit model is certainly violated.

${ }^{14}$ There is a substantial literature which attempts to establish the incidence of credit constraints in general populations. "Excess sensitivity" (Euler equation) studies (Zeldes, 1989, Runkle, 1991) and the analysis of direct survey questions (Jappelli, 1990) have already been mentioned. More recently, Gross and Souleles (2003) provide interesting evidence of binding borrowing constraints based on responses to changes in credit card borrowing limits.
} 
match) are not collateralisable. The literature on consumption smoothing during unemployment has documented higher marginal propensities to consume out of transitory income among low wealth households. However, as discussed above, the interpretation of this as evidence that the unemployed face borrowing constraints is problematic.

Carroll, (2001) suggests that one kind of evidence for borrowing constraints are "spikes" at zero net assets. Note that the lower left panel of Figure 8 exhibits exactly such a "spike". In this cumulative distribution, the mass of observations at exactly zero net assets (about a quarter of the sample) appears as a vertical jump at zero.

Alternative evidence for borrowing constraints comes from direct survey questions. This is the principal evidence that we present in this paper, and, as far as we are aware, this is the first such evidence for job losers/unemployed. The 1995 Canadian Out of Panel asked recent job losers two sets of questions about their ability to borrow. They were asked subjective questions as follows:

- If you needed it, COULD you borrow money from a friend, family, or a financial institution in order to increase your household expenditures?

If the answer to this question was negative, the respondent was then asked:

- Suppose you COULD borrow money from one of these sources at $11 \%$ interest per year, to be paid back starting in one year. WOULD you borrow money to increase your weekly spending on household expenses? ? $^{15}$

A question similar to the first of these was previously posed to low income households in Chicago, as reported by Mayer and Jencks (1989). We take the answers to the first question as informative about access to credit. If a respondent says "no" to the first question and "yes" to the second, we take them to be reporting that they are constrained (in the sense that their Euler equation does not hold with equality.)

Second, respondents were asked a series of questions about credit applications and the outcomes of those applications, similar to the (U.S.) Survey of Consumer Finance questions studied by Jappelli (1990). These questions were as follows:

\footnotetext{
${ }^{15}$ Nominal prime interest rate at this time in Canada was about $7 \%$.
} 
- At any time since your job ended on [date of job loss] did you or any member of your household apply for a loan at a bank or financial institution, or for credit with any credit company? (Applied)

- Were any of your requests for credit or a loan turned down? (Declined)

- Were you, or any member of your household, given as much credit as you applied for? (Not Full Amount)

- Were you later able to obtain the full amount you requested by reapplying to the same institution or by applying elsewhere? (Got Later)

- Was there any time since [date of job loss] that you or any member of your household thought of applying for credit at a particular place, but changed your mind because you thought you might be turned down? (Discouraged)

Responses to the "subjective" questions are summarized in the top panel of Table 4. Among respondents not working at the time of interview, more than 30 percent report that they could not borrow. The corresponding number for those back in employment is almost 10 percentage points lower. Overall, about a quarter of recent job losers report no access to credit. Of those who report that they are unable to borrow, only a fraction (13 percent among those not working) report that they would borrow if they could. Thus, only a small fraction of the sample report being "constrained" in the sense of an Euler equation violation. However, uncertainty about future employment and the possibility that credit constraints may bind in the future may be dampening the desire to borrow.

The bottom panel of Table 4 summarizes responses to the "objective" questions. About a quarter of recent job losers applied for some kind of credit before the 1st interview. ${ }^{16}$ Of those, about a quarter were constrained in the sense that their application was declined or they did not get the full amount, and were not later able to get the full amount. Thus about 6 percent of the full sample are constrained by this definition. Following Jappelli, we also consider a broader definition of constrained that includes those who did not apply because they anticipated that an application would not be successful (the discouraged). These are about 8 percent of the sample, so that about 14 percent of the sample are constrained by this

\footnotetext{
${ }^{16}$ The data contain some information on the type of credit our respondents applied for. Personal loans, car loans and credit cards were the most common. Although the respondents could list up to 3 different kinds of credit, more than $90 \%$ listed only one type. Thus we can also calculate rough rejection rates by type of credit. These were much higher for unsecured debt (credit cards and consolidation loans) than for secured debt (car loans and mortgages).
} 
broader definition. In comparison, Jappelli (1990) finds 19 percent of households in the 1983 US Survey of Consumer Finance report being constrained in this sense over a period of several years prior to the interview.

Figure 10 illustrates the age patterns in our measures of credit access and credit constrained. The top panel is based on the "subjective" questions. The sample is divided into three age groups (26-35, 36-45, and 46-55) and each group is divided into those that are and are not employed at the time of the (first) interview. Among respondents aged 26-35, not in work at the interview date, 30 percent could not borrow, and 5 percent would if they could. The fraction that report that they could not borrow falls with age among the employed, but rises with age among those not in work. The fraction that are constrained (can't borrow and would) falls with age for both the employed and unemployed.

The lower panel of Figure 10 is based on the "objective" questions. We divide the sample into the same three age categories. However, as these questions refer to anytime since the job loss, we do not divide by current employment status. Among the youngest group, 9\% experience a binding borrowing constraint in the sense of being unable to obtain credit for which they applied, while $18 \%$ report being constrained in the broader sense of either being unable to obtain credit for which they applied or deciding not to apply in anticipation of the application being unsuccessful. By either the broad or narrow measure, the incidence of (binding) borrowing constraints falls with age. Relative to the "subjective" questions, the "objective" questions suggest a greater incidence of binding constraints at all ages. This is quite natural because the former refer to the time of the interview, while the latter refer to any time since the job loss.

To model the characteristics of the credit constrained, we estimate a series of probit models. We have a core set of predictor variables including just characteristics of the respondent and her household; and an extended set which adds type of job separation and household financial circumstances at the time of job loss. The results are presented in Tables 5 through 7 .

Table 5 presents empirical (probit) models of the response to the "could borrow" question. We have coded a negative response as a 1 and so these are models of the probability that the respondent is unable to borrow. In Table 6 we turn from the issue of whether a household 
could borrow to the issue of whether they face (or have faced) a binding constraint. Here a respondent is coded 1 if they report that they are unable to borrow and would like to.

In both tables, we initially split the sample into those respondents who were not employed at the interview date (left panel) and those that were (middle panel). In both tables, likelihood ratio tests indicated that we could not reject pooling the employed and unemployed (allowing for an intercept shift) when using the richer specification. This was not true, however, for the sparser specification. Accordingly, we also estimated the extended model - augmented with a dummy for employed at the interview - on the pooled sample.

Across samples and specifications, some common patterns emerge. Women are more likely to be unable to borrow, as are the less educated and visible minorities. Households with liquid assets or owning their home are more likely to be able to borrow. The home ownership effect is partially offset by having a mortgage. Current non-employment appears to have an independent effect (reducing ability to borrow) even after controlling for other factors. These effects are economically significant. For example, college education reduces the probability of being unable to borrow by between a quarter and a half.

Turning to Table 6 , we see fewer statistically significant effects, in part because we are modelling an infrequent event. Nevertheless, visible minorities, those with little education and non home-owners are more likely to experience a binding borrowing constraint.

Table 7 explores the alternative measure of constrained which is based on the "objective" questions (the broad measure, including "discouraged"). Since these questions refer to the entire period since the initial job loss, we pool those who are currently working with those that are not. In other respects, we follow the previous two tables: we estimated two probit models, a sparse specification and a richer empirical model. Once again, the less educated and visible minorities are more likely to be constrained. Households with liquid assets or owning their home are less likely to be constrained. Pre-existing unsecured debt increases the likelihood of being constrained.

A natural question is whether our measures of borrowing constraints identify the same set of households as traditional approaches (based on wealth or liquid asset measures). Table 8 addresses this question. We construct two measures: whether the household had any liquid 
assets at all, and whether they had at least 2 months usual income in liquid assets. The latter is similar to the measure used by Zeldes (1989). We construct both these measures at job loss and at the first interview. The first column of Table 8 gives the actual agreement between the various measures - the fraction of the sample for which a pair of measures takes the same values (note that all the measures are binary). In considering the agreement between two measures, it is important to note that the further the means of the two measures are from .5 , the greater the degree of agreement that one would expect to arise simply by chance. The second column of Table 8 gives the degree of agreement between each pair of measures that one would expect to arise by chance. The third column of Table 8 gives the Kappa statistic, which measures the degree of actual agreement, accounting for the degree of agreement which would arise by chance. A value of 0 indicates the same agreement as would arise by chance. A value of 1 indicates complete agreement. Table 8 illustrates that there is a statistically significant degree of agreement between all the pairs of measures, but agreement is by no means perfect. Whether the household has any assets seems to be a slightly better measure of whether they face borrowing constraints than whether they had 2 months of assets. On balance, our subjective and objective measures of borrowing constraints agree more strongly with each other than with the asset measures.

\section{Consumption Growth}

The final element of our empirical analysis is to examine the consumption growth of households between the first interview in the third quarter after job loss and second interview in the fifth quarter after job loss. Consumption growth is defined as the change in the logarithm of total expenditure. This is divided by the number of weeks between the first and second interview to give an annual rate. In Table 9 we report a series of consumption growth regressions. The first column of Table 9 reports a regression of consumption growth on a constant, age, the change in household size between the first and second interview, and dummy variables capturing the responses to the subjective questions regarding ability and desire to borrow at the first interview. Those who report a binding constraint (report that they could not borrow, but would if they could) exhibit very high consumption growth. Their consumption growth is 
statistically (and economically) different from the rest of the sample. The consumption growth of those who say they could not borrow, but are not constrained, is not statistically different from those who say they could borrow.

The remaining columns report consumption growth regressions that have the form of excess sensitivity tests. In particular, we regress consumption growth on a constant, age, the change in household size, and lagged income. The idea is that, to the extent that it is in the information set at the first interview, lagged income should not predict consumption growth between the first and second interview. The second column of Table 9 indicates that lagged income does predict consumption growth among our respondents. The third and fourth columns of Table 9 indicate that this correlation is driven by those households with no liquid assets. These kinds of result are sometimes taken as evidence of liquidity constraints (as in Zeldes, 1989), and the heterogeneity by wealth levels echoes previous findings (both in the literature on consumption smoothing over unemployment and in the broader consumption literature). In the final two columns, we successively eliminate from the sample those who report a binding borrowing constraint (cannot borrow but would) and those who cannot borrow. Here our empirical strategy is very similar to Jappelli et al. (1998) except that we have exact (rather than imputed) information on borrowing constraints. Our results indicate that excess sensitivity is not limited to those who report a binding borrowing constraint, or even to those who report they cannot borrow. This suggests that the excess sensitivity must arise, at least in part, for other reasons, such as the nonseparability of consumption and labour supply, or because of correlations between lagged income and future uncertainty. Because we do not find excess sensitivity among high wealth households, the latter explanation is particularly attractive. ${ }^{17}$ The bottom line, however, is that in interpreting excess sensitivity and high marginal propensities to consume out of transitory income as evidence of binding borrowing constraints, the literature on consumption smoothing during unemployment may have overestimated the empirical importance of binding borrowing constraints.

\footnotetext{
${ }^{17}$ Moreover, the results in this table are robust to conditioning on changes in employment.
} 


\section{Conclusions}

In this paper, we have emphasized a series of related ideas. Unemployment insurance is more valuable when self-insurance is more difficult. Self-insurance is more difficult when the cost of borrowing and the cost of saving are high. The cost of borrowing depends on credit markets, and in particular, is effectively infinite for households facing a binding borrowing constraint. The cost of savings depends on the timing of income and the timing of needs, as well as private and market discount rates. Heterogeneity in these factors could lead to the empirical heterogeneity in asset holdings, and in marginal propensities to consume, that has been documented among job losers. Heterogeneity in these factors would also imply differences in the value of unemployment insurance.

We developed a simple life-cycle model to illustrate these connections. Our model illustrates that in the presence of borrowing constraints unemployment insurance may have an additional benefit that derives from smoothing consumption over time after job loss. Borrowing constraints can also dampen the moral hazard. These effects of borrowing constraints can raise the optimal replacement rate. In addition, optimal replacement rates vary substantially with the age at job loss and the strength of the retirement saving motive. In our model, these are the factors that determine the cost of accumulating and holding a buffer stock.

Empirically, we provided new evidence on the financial resources of job losers, on the incidence of borrowing constraints after job loss and on subsequent consumption growth. There is enormous heterogeneity in liquid asset holdings at job loss. Life-cycle circumstances that alter the costs of savings explain some of this variation. For example, holdings of liquid assets that can be used to buffer employment shocks rise with age; are lower for households with children (high needs); and are lower for households with (illiquid) pension wealth.

With respect to the empirical importance of borrowing constraints, the data deliver a mixed message. On the one hand, while twenty-five percent of job losers report that they could not borrow, a much smaller fraction report being "constrained" in the sense that they would borrow if they could. Both groups are significantly smaller than (and not a strict subset of) the set of households that report having no liquid assets at job loss. Moreover, "excess sensitivity" (of consumption growth to lagged income) is not limited to those who report being 
constrained, or even to those who report that they could not borrow. Thus the literature may have been too quick to interpret high marginal propensities to consume among low wealth job losers as evidence of borrowing constraints. Precautionary saving against the risk of ongoing unemployment or employment instability (and also the related risk that borrowing constraints may bind in the future) is likely to play an important role.

On the other hand, even in the context of a fairly generous Canadian unemployment insurance system, a small group of job losers report experiencing binding credit constraints and exhibit very high consumption growth - suggesting that they are unable to smooth consumption over time, and that they experience significant hardship. Further, as first stressed by Deaton (1991), even if borrowing constraints do not bind, the inability to borrow can interact with uncertainty to affect both behaviour and welfare.

Ongoing uncertainty is not present in our model, or in the Bailey model, where there is only one point in time at which job loss may occur. Models with ongoing uncertainty are unlikely to yield many analytical results. They can of course, be approached numerically. A key challenge is to do so in ways that remain flexible with respect to the cost of savings, and the patience of agents.

The life-cycle approach to unemployment insurance taken in this paper suggests a number of important policy implications. An obvious implication is that the design of public pensions and public unemployment insurance systems are interdependent. To the extent that public pensions mean that workers retirements savings are not available to smooth a temporary income shock (either directly or as collateral) they may make unemployment insurance more valuable.

However, the most important implication of our analysis is that models that ignore the kind of heterogeneity we have documented are likely to provide an incomplete guide to policy. Our data contain many workers for whom unemployment insurance has little value. Because circumstances or other savings motives makes it easy for them to hold a buffer of liquid assets, or because they have good access to credit markets, self-insurance is a reasonable option. For other workers in our data, this is not the case. Even without redistribution between groups, the optimal single unemployment insurance system must depend on the weight society places on the welfare of different groups. Moreover, differential benefits by age or family type (for 
example, higher benefits to families with children) may be desirable on insurance grounds alone. This is because the cost of self-insurance, and hence the value of unemployment insurance, may differ across ages and family types. Of course, this needs to be balanced against differences across groups in the extent of moral hazard.

\section{References}

Alan, S. and M. Browning (2003). "Estimating Intertemporal Allocation Parameters Using Simulated Residual Estimation." Institute of Economics, University of Copenhagen CAM Working paper 2003-03.

Attanasio,O., J.Banks, C. Meghir and G. Weber, (1999). "Humps and Bumps in Consumption." Journal of Business Economics and Statistics, 17(1):22-35.

Attanasio, O., and A. Brugiavini, (2003). "Social security and household savings" Quarterly Journal of Economics 118(3):1075-1120

Attanasio, O., and S. Rohwedder, (2004). "Pension Wealth and Household Saving: Evidence from Pension Reforms in the U.K." American Economic Review 93(5):1499-1521

Bailey, M., (1978). "Some Aspects of Optimal Unemployment Insurance." Journal of Public Economics, 10(3), 379-402.

Bloemen, H.G. and E.G.F. Stancanelli, (2001). "Financial Wealth, Consumption Smoothing, and Income Shocks Due to Job Loss." Research Memorandum 2001-36, Free University, Amsterdam.

Browning, M. and T.F. Crossley, (2001), "Unemployment Benefit Levels and Consumption Changes." Journal of Public Economics, 80(1):1-23.

Carroll, C., (1997), "Buffer Stock Saving and the Life Cycle/Permanent Income Hypothesis." Quarterly Journal of Economics, 107(1):1-56.

Carroll, C., (2001), "A Theory of the Consumption Function, With and Without Liquidity Constraints" Journal of Economics Perspectives, 15(3):23-46 
Chetty, R., (2004). "Optimal Unemployment Insurance When Income Effects are Large" NBER Working Paper 10500

Costain, J., (1999). "Unemployment Insurance with Endogenous Search Intensity and Precautionary Savings.” Draft, Universitat Pompeu Fabra.

Deaton, A., (1991). "Savings and Liquidity Constraints." Econometrica, 59:1221-48.

Diamond, P. and J.A. Mirrlees, (1979). "A Model of Social Insurance with Variable Retirement." Journal of Public Economics, 10:295-336.

Dynan, K.E., J. Skinner and S.P. Zeldes, (2002). "The Importance of Bequests and Life-Cycle Saving in Capital Accumulation: A New Answer." American Economic Review, Papers and Proceedings. 92(2):274-278.

Dynarski, S. and J. Gruber, (1997). "Can Families Smooth Variable Earnings?" Brookings Papers on Economics Activity, 1997(1):229-303.

Engen, E. M. and and J. Gruber, (2001). "Unemployment Insurance and Precautionary Savings," Journal of Monetary Economics, 47(3):545-79.

Gourinchas, P-0., and J. A. Parker, (2002). "Consumption Over the Life Cycle," Econometrica, $70(1): 47-89$.

Gross, D. and N. Souleles, (2002). "Do liquidity Constraints and Interest Rates Matter for Consumer Behaviour? Evidence from Credit Card Data." Quarterly Journal of Economics, 117(1):149-85.

Gruber, J., (1997). "The Consumption Smoothing Benefit of Unemployment Insurance." American Economic Review, 87(1), 192-205.

Gruber, J., (2001). "The Wealth of the Unemployed." Industrial and Labor Relations Review, 55(1):79-94.

Hansen, G.D. and A. Imrohoroglu, (1992). "The Role of Unemployment Insurance in an Economy with liquidity Constraints and Moral Hazard." Journal of Polictical Economy, 100(1):118-142. 
Jappelli, T., (1990). "Who is Credit Constrained in the U.S. Economy?" Quarterly Journal of Economics, 105(1):219-234.

Jappelli, T., J-S. Piske and N. Souleles, (1998). "Testing for Liquidity Constraints in Euler Equations with Complementary Data Sources." Review of Economics and Statistics, $80(2): 251-262$.

Lentz, R. (2003) "Optimal Unemployment Insurance in an Estimated Job Search Model with Savings" Boston University, Draft.

Manning, W., N.Duan and W. Rogers, (1987), "Monte Carlo Evidence on the Choice Between Sample Selection and Two-Part Models." Journal of Econometrics, 35:59-82.

Mayer, S.E. and C. Jencks, (1989). "Poverty and the Distribution of Material Hardship." Journal of Human Resources, 24(1):88-113.

Rendon, S. (2002). "Job Search and Asset Accumulation Under Borrowing Constraints." Working paper 02-52, Universidad Carlos III de Madrid.

Runkle, D.E., (1991). "Liquidity Constraints and the Permanent Income Hypothesis: Evidence from Panel Data." Journal of Monetary Economics, 27:73-98.

Samwick, A.A., (1998). "Discount Rate Heterogeneity and Social Security Reform." Journal of Development Economics, 57:117-146.

Sullivan, J.X., (2002). "Borrowing During Unemployment : Unsecured Debt as a Safety Net." Working paper, University of Notre Dame.

Zeldes, S., (1989). "Consumption and Liquity Constraints: an Empirical Investigation." Journal of Political Economy, 96:305-346. 


\section{Appendix: Solving the Model}

This appendix describes explicitly the recursive solution of the model. We solve for the optimal choices of consumption at each stage and investment after job loss. The tax rate, $\tau^{u}$, is determined by the government revenue equation in the text. The system reduces to 3 nonlinear equations determining $A_{1}, I$ and $\tau^{u}$ which we solve numerically.

Stage 3: In the third (retirement) stage of life, the value function is

$$
V_{3}\left(A_{2} ; I\right)=\max _{c_{t}} \int_{T_{2}}^{T_{3}} u\left(c_{t}\right) d t
$$

Subject to:

$$
\int_{T_{2}}^{T_{3}} c_{t} d t=A_{2}+\tau^{r}\left(Y_{1}+Y_{2}(I)\right)
$$

where $I=-1$ indicates the individual was not displaced in period 2. Note that the borrowing constraint, if present, is irrelevant because the constraint that terminal assets are zero and the assumption that $\delta=0$ mean consumption is spread evenly through the stage. Associating $\lambda_{3}$ with the budget constraint (13) and using the envelope theorem,

$$
\begin{gathered}
\frac{\partial V_{3}}{\partial A_{2}}=\lambda_{3} \\
\frac{\partial V_{3}}{\partial I}=\lambda_{3} \cdot \tau^{r} \cdot\left(\frac{\partial E_{2}}{\partial I}+b Y_{1}\right)
\end{gathered}
$$

These expressions are used in solving for assets and investment in earlier stages.

Stage 2 (not displaced): In the second stage there are two cases: displaced $(d)$ or not $(n)$. If the agent is not displaced, her value function is

$$
V_{2}^{n}\left(A_{1}\right)=\max _{c_{t}, A_{2}} \int_{T_{1}}^{T_{2}} u\left(c_{t}\right) d t+V_{3}\left(A_{2} ; I=-1\right)
$$

subject to

$$
\int_{T_{1}}^{T_{2}} c_{t} d t=A_{1}-A_{2}+Y_{2}^{n}\left(1-\tau^{r}-\tau^{u}\right)
$$


As with stage 3 , consumption will be constant within the stage. Associating the multiplier $\lambda_{2 n}$ with constraint (14) gives the Euler equation

$$
\begin{aligned}
& \frac{\partial V_{2}^{n}}{\partial A_{2}}:-\lambda_{2 n}+\frac{\partial V_{3}}{\partial A_{2}}+\mu_{2 n}=0 \\
& \mu_{2 n} \geq 0, \quad A_{2 n} \geq-\phi .
\end{aligned}
$$

If there is no borrowing constraint, or the constraint is not binding, $\mu_{2 n}=0$ and consumption will be smooth between stages 2 and 3 .

Stage 2 (displaced): No credit constraint We consider optimal choices after displacement first for the case with no credit constraint and in the next subsection for the case with credit constraints.

If the worker is displaced her value function is

$$
V_{2}^{d}\left(A_{1}\right)=\max _{c_{t}, A_{2}, I} \int_{T_{1}}^{T_{2}} u\left(c_{t}\right) d t+V_{3}\left(A_{2,} Y_{2}(I)\right)
$$

subject to

$$
\begin{aligned}
\int_{T_{1}}^{T_{2}} c_{t} d t & =A_{1}-A_{2}+b Y_{1} I\left(1-\tau^{r}\right)+E_{2}^{d}(I)\left(1-\tau^{r}-\tau^{u}\right) \\
0 & \leq I \leq T_{2}-T_{1}
\end{aligned}
$$

As before, consumption will be constant within the stage. Associating the multiplier $\lambda_{2 d}$ with constraint (16) gives the Euler equation

$$
\frac{\partial V_{2}^{d}}{\partial A_{2}}: \quad \frac{\partial V_{3}}{\partial A_{2}}-\lambda_{2 d}=0
$$

Since we know consumption in the final period, we can solve directly for consumption in period 2 and for $\lambda_{2 d}$.

Turning to investment behaviour, the absence of a credit constraint means that the choice over $I$ can be considered independently from the choice of $A_{2 .}$.

\section{Stage 2 (displaced): With credit constraint}

The presence of the credit constraint means the timing of income within the second stage may matter. The length of investment and the path of consumption will be jointly determined 
rather than being separable decisions as in the absence of credit constraints. Therefore, it is useful to divide the stage into an earnings and an investment substage.

\section{Earnings sub-stage}

$$
V_{2 E}^{d}\left(A_{1+I}, I\right)=\max _{c_{t E}, A_{2}} \int_{T_{1}+I}^{T_{2}} u\left(c_{t E}\right) d t+V_{3}\left(A_{2}, Y_{2}(I)\right)
$$

subject to

$$
\begin{aligned}
\int_{T_{1}+I}^{T_{2}} c_{t} d t & =A_{1}-A_{2}+E_{2}^{d}(I)\left(1-\tau^{r}-\tau^{u}\right) \\
A_{2} & \geq-\phi
\end{aligned}
$$

Associating the multiplier $\lambda_{2 E}$ with the first constraint and $\mu_{2 E}$ with the second constraint ${ }^{18}$ gives first-order conditions:

$$
\begin{aligned}
& \frac{\partial V_{2 E}^{d}}{\partial A_{2}}: \frac{\partial V_{3}}{\partial A_{2}}-\lambda_{2 E}+\mu_{2 E}=0 \\
& \mu_{2 E} \geq 0, \quad A_{2} \geq-\phi
\end{aligned}
$$

Using the envelope theorem,

$$
\begin{aligned}
& \frac{\partial V_{2 E}^{d}\left(A_{1+I}, I\right)}{\partial A_{1+I}}=\lambda_{2 E} \\
& \frac{\partial V_{2 E}^{d}\left(A_{1+I}, I\right)}{\partial I}=-u\left(c_{2 E}\right)+\frac{\partial V_{3}}{\partial I}+\lambda_{2 E}\left(\frac{\partial E_{2}^{d}}{\partial I}\left(1-\tau^{r}-\tau^{u}\right)+c_{2 E}\right)
\end{aligned}
$$

Investment sub-stage

$$
V_{2 I}^{d}\left(A_{1}\right)=\max _{c_{t I}, A_{2}, I} \int_{T_{1}}^{T_{1+I}} u\left(c_{t I}\right) d t+V_{2 E}^{d}\left(A_{1+I}, I\right)
$$

subject to

$$
\begin{aligned}
\int_{T_{1}}^{T_{1+I}} c_{t I} d t & =A_{1}-A_{1+I}+b Y_{1} I\left(1-\tau^{r}\right) \\
A_{1+I} & \geq-\phi
\end{aligned}
$$

\footnotetext{
${ }^{18}$ As before, consumption must be constant within each sub-stage because no new information arrives within each sub-stage and the interest rate equals the discount rate. This in turn means that if the constraint binds at all in a sub-stage, it must bind at the end of that sub-stage.
} 
Associating the multiplier $\lambda_{2 I}$ with the first constraint and $\mu_{2 I}$ with the second constraint, gives the first-order condition for savings:

$$
\begin{aligned}
\frac{\partial V_{2 I}^{d}}{\partial A_{1+I}}: \quad & \frac{\partial V_{2 E}^{d}}{\partial A_{1+I}}-\lambda_{2 I}+\mu_{2 I}+0 \\
\mu_{2 I} & \geq 0, \quad A_{1+I} \geq-\phi
\end{aligned}
$$

The equation determining investment is given by the first-order condition from maximising equation (5) with respect to $I$.

$$
\frac{\partial V_{2 I}^{d}}{\partial I}=0=\frac{\partial V_{2 E}^{d}}{\partial I}+u\left(c_{2 I}\right)+\lambda_{2 I} b Y_{1}\left(1-\tau^{r}\right)-\lambda_{2 I} c_{2 I}
$$

Substituting in from equation (22) and rearranging,

$$
\begin{aligned}
\frac{\partial E_{2}^{d}}{\partial I}\left[\lambda_{3} \tau^{r}+\lambda_{2 E}\left(1-\tau^{r}-\tau^{u}\right)\right]+b Y_{1}\left[\lambda_{2 I}\left(1-\tau^{r}\right)+\right. & \left.\lambda_{3} \tau^{r}\right] \\
& =u\left(c_{2 E}\right)-u\left(c_{2 I}\right)+\lambda_{2 I} c_{2 I}-\lambda_{2 E} c_{2 E} .
\end{aligned}
$$

Using the definition of $E_{2}^{d}$, this can be rearranged as:

$$
\begin{gathered}
w^{\prime}(I)\left(T_{2}-T_{1}-I\right)\left[\lambda_{3} \tau^{r}+\lambda_{2 E}\left(1-\tau^{r}-\tau^{u}\right)\right]+b Y_{1}\left[\lambda_{2 I}\left(1-\tau^{r}\right)+\lambda_{3} \tau^{r}\right] \\
=w(I)\left[\lambda_{3} \tau^{r}+\lambda_{2 E}\left(1-\tau^{r}-\tau^{u}\right)\right]+\Psi
\end{gathered}
$$

where we define $\Psi$ by

$$
\Psi=\left[u\left(c_{2 E}\right)-u\left(c_{2 I}\right)\right]-\left[\lambda_{2 E} c_{2 E}-\lambda_{2 I} c_{2 I}\right] .
$$

Taking a first-order approximation to $u\left(c_{2 E}\right)$ around $c_{2 I}$ and substituting gives

$$
\begin{aligned}
\Psi & =u^{\prime}\left(c_{2 I}\right) c_{2 E}-\lambda_{2 E} c_{2 E} \\
& =\left(u^{\prime}\left(c_{2 I}\right)-u^{\prime}\left(c_{2 E}\right)\right) c_{2 E}
\end{aligned}
$$

Taking an approximation for $u^{\prime}\left(c_{2 E}\right)$ around $c_{2 I}$

$$
\begin{aligned}
\Psi & =-u^{\prime \prime}\left(c_{2 E}\right)\left(c_{2 E}-c_{2 I}\right) c_{2 E} \\
& =\left[-\frac{u^{\prime \prime}\left(c_{2 E}\right)}{u^{\prime}\left(c_{2 E}\right)} c_{2 E}\right]\left(c_{2 E}-c_{2 I}\right) u^{\prime}\left(c_{2 E}\right)
\end{aligned}
$$


which gives

$$
\Psi \approx \gamma \Delta c_{2 E} u^{\prime}\left(c_{2 E}\right)
$$

where $\gamma$ is the coefficient of relative risk aversion which captures the degree of aversion to fluctuations in consumption.

\section{Appendix: Deriving Optimal Benefit}

In the text we provide brief derivation of an expression to show the trade-off in setting the optimal benefit. This appendix provides the details of the derivation.

We assume there is no third period in the model and so no retirement tax and no assets are held at the end of the second period.

$$
V_{1}=\max _{c_{t}, A_{1}} \int_{0}^{T_{1}} u\left(c_{t}\right) d t+\pi V_{2}^{d}\left(A_{1}\right)+(1-\pi) V_{2}^{n}\left(A_{1}\right)
$$

Substituting in optimal values for consumption, investment and saving at each stage:

$$
\begin{aligned}
V_{1}= & u\left(\frac{Y_{1}\left(1-\tau^{u}\right)-A_{1}^{*}}{T_{1}}\right) T_{1} \\
& +\pi\left(u\left(\frac{A_{1}^{*}+b Y_{1} I^{*}-A_{1+I}^{*}}{I^{*}}\right) I^{*}+u\left(\frac{A_{1+I}^{*}+E_{2}^{d}\left(I^{*}\right)\left(1-\tau^{u}\right)}{T_{2}-T_{1}-I^{*}}\right)\left(T_{2}-T_{1}-I^{*}\right)\right) \\
& +(1-\pi) u\left(\frac{A_{1}^{*}+Y_{2}^{n}\left(1-\tau^{u}\right)}{T_{2}-T_{1}}\right)\left(T_{2}-T_{1}\right)
\end{aligned}
$$

We take the derivative with respect to the replacement rate, $b$, and substitute $\lambda_{i}=\partial u / \partial c_{i}$, where $i \in\{1, n, I, E\}$ correspond, respectively, to stage 1, the non-displaced stage, the investment sub-stage post job loss and the earnings sub-stage after returning to work. We use the envelope theorem to ignore indirect effects of changing benefits operating through optimised values of $I, A_{1}, A_{1+I}$. This gives equation (11) in the text.

$$
\frac{\partial V_{1}}{\partial b}=-\lambda_{1} Y_{1} \frac{\partial \tau^{u}}{\partial b}+\pi\left(\lambda_{I} Y_{1} I-\lambda_{E} E_{2}^{d}(I) \frac{\partial \tau^{u}}{\partial b}\right)-(1-\pi) \frac{\partial \tau^{u}}{\partial b} \lambda_{n} Y_{2}^{n}
$$

We set $\partial V_{1} / \partial b=0$, and rearrange

$$
\pi\left(Y_{1} I \lambda_{I}-E_{2}^{d}(I) \frac{\partial \tau^{u}}{\partial b} \lambda_{E}\right)=(1-\pi) Y_{2}^{n} \frac{\partial \tau^{u}}{\partial b} \lambda_{n}+Y_{1} \frac{\partial \tau^{u}}{\partial b} \lambda_{1}
$$


We take first-order approximations of marginal utility around consumption in the state with no job loss, $c_{n}$,

$$
\begin{gathered}
\lambda_{i} \approx \lambda_{n}-u^{\prime \prime}\left(c_{n}\right)\left(c_{n}-c_{i}\right) \\
\pi\left(Y_{1} I \lambda_{n}-Y_{1} I u^{\prime \prime}\left(c_{n}\right)\left(c_{n}-c_{I}\right)-E_{2}^{d}(I) \frac{\partial \tau^{u}}{\partial b}\left(\lambda_{n}-u^{\prime \prime}\left(c_{n}\right)\left(c_{n}-c_{E}\right)\right)\right) \\
=(1-\pi) Y_{2}^{n} \frac{\partial \tau^{u}}{\partial b} \lambda_{n}+Y_{1} \frac{\partial \tau^{u}}{\partial b} \lambda_{n}-Y_{1} \frac{\partial \tau^{u}}{\partial b} u^{\prime \prime}\left(c_{n}\right)\left(c_{n}-c_{1}\right)
\end{gathered}
$$

Dividing through by $\lambda_{n}$

$$
\begin{aligned}
& \pi\left(Y_{1} I-Y_{1} I \frac{u^{\prime \prime}\left(c_{n}\right)}{u^{\prime}\left(c_{n}\right)}\left(c_{n}-c_{I}\right)-E_{2}^{d}(I) \frac{\partial \tau^{u}}{\partial b}\left(1-\frac{u^{\prime \prime}\left(c_{n}\right)}{u^{\prime}\left(c_{n}\right)}\left(c_{n}-c_{E}\right)\right)\right) \\
= & (1-\pi) Y_{2}^{n} \frac{\partial \tau^{u}}{\partial b}+Y_{1} \frac{\partial \tau^{u}}{\partial b}-Y_{1} \frac{\partial \tau^{u}}{\partial b} \frac{u^{\prime \prime}\left(c_{n}\right)}{u^{\prime}\left(c_{n}\right)}\left(c_{n}-c_{I}\right)
\end{aligned}
$$

Replacing

$$
\begin{gathered}
\gamma=-\frac{u^{\prime \prime}\left(c_{n}\right)}{u^{\prime}\left(c_{n}\right)} c_{n} \\
\pi\left(Y_{1} I-E_{2}^{d}(I) \frac{\partial \tau^{u}}{\partial b}+\gamma \frac{\left(c_{n}-c_{I}\right)}{c_{n}} Y_{1} I-\gamma \frac{\left(c_{n}-c_{E}\right)}{c_{n}} \frac{\partial \tau^{u}}{\partial b} E_{2}^{d}(I)\right) \\
=(1-\pi) Y_{2}^{n} \frac{\partial \tau^{u}}{\partial b}+Y_{1} \frac{\partial \tau^{u}}{\partial b}+Y_{1} \frac{\partial \tau^{u}}{\partial b} \gamma \frac{\left(c_{n}-c_{1}\right)}{c_{n}}
\end{gathered}
$$

Adding and subtracting $\pi Y_{1} I \gamma\left(c_{n}-c_{E}\right) / c_{n}$ from the left hand side,

$$
\left.\begin{array}{rl} 
& \pi\left(\begin{array}{c}
Y_{1} I-E_{2}^{d}(I) \frac{\partial \tau^{u}}{\partial b}+\gamma \frac{\left(c_{n}-c_{I}\right)}{c_{n}} Y_{1} I-\gamma \frac{\left(c_{n}-c_{E}\right)}{c_{n}} \frac{\partial \tau^{u}}{\partial b} E_{2}^{d} \\
+\gamma \frac{\left(c_{n}-c_{E}\right)}{c_{n}} Y_{1} I-\gamma \frac{\left(c_{n}-c_{E}\right)}{c_{n}} Y_{1} I
\end{array}\right) \\
= & (1-\pi) Y_{2}^{n} \frac{\partial \tau^{u}}{\partial b}+Y_{1} \frac{\partial \tau^{u}}{\partial b}+Y_{1} \frac{\partial \tau^{u}}{\partial b} \gamma \frac{\left(c_{n}-c_{1}\right)}{c_{n}} \\
& \pi\left(\begin{array}{c}
Y_{1} I-E_{2}^{d}(I) \frac{\partial \tau^{u}}{\partial b}+\gamma \frac{\left(c_{n}-c_{E}\right)}{c_{n}}\left(Y_{1} I-\frac{\partial \tau^{u}}{\partial b} E_{2}^{d}\right) \\
-\gamma Y_{1} I\left(\frac{\left(c_{n}-c_{E}\right)}{c_{n}}-\frac{\left(c_{n}-c_{I}\right)}{c_{n}}\right)
\end{array}\right) \\
= & (1-\pi) Y_{2}^{n} \frac{\partial \tau^{u}}{\partial b}+Y_{1} \frac{\partial \tau^{u}}{\partial b}+Y_{1} \frac{\partial \tau^{u}}{\partial b} \gamma \frac{\left(c_{n}-c_{1}\right)}{c_{n}}
\end{array}\right)
$$




$$
\begin{aligned}
& \pi\left(Y_{1} I-E_{2}^{d}(I) \frac{\partial \tau^{u}}{\partial b}+\gamma\left[\frac{\left(c_{n}-c_{E}\right)}{c_{n}}\right]\left(Y_{1} I-\frac{\partial \tau^{u}}{\partial b} E_{2}^{d}\right)+\gamma\left[\frac{\left(c_{E}-c_{I}\right)}{c_{n}}\right] Y_{1} I\right) \\
= & (1-\pi) Y_{2}^{n} \frac{\partial \tau^{u}}{\partial b}+Y_{1} \frac{\partial \tau^{u}}{\partial b}+Y_{1} \frac{\partial \tau^{u}}{\partial b} \gamma \frac{\left(c_{n}-c_{1}\right)}{c_{n}}
\end{aligned}
$$

Finally, putting the marginal benefit terms on the left hand side and the marginal cost terms (through higher taxes) on the right hand side gives equation (12) in the text:

$$
\begin{aligned}
& \pi Y_{1} I\left(1+\gamma\left[\frac{\left(c_{n}-c_{E}\right)}{c_{n}}\right]+\gamma\left[\frac{\left(c_{E}-c_{I}\right)}{c_{n}}\right]\right) \\
= & \frac{\partial \tau^{u}}{\partial b}\left\{(1-\pi) Y_{2}^{n}+Y_{1}\left(1+\gamma \frac{\left(c_{n}-c_{1}\right)}{c_{n}}\right)+\pi E_{2}^{d}(I)\left(1+\gamma\left[\frac{\left(c_{n}-c_{E}\right)}{c_{n}}\right]\right)\right\}
\end{aligned}
$$




\section{Tables}

Table 1: Notation and Earnings

\begin{tabular}{|c|c|c|}
\hline $\begin{array}{l}c_{t}: \\
A_{s}: \\
w_{s}: \\
Y_{s}: \\
E_{s}:\end{array}$ & $\begin{array}{l}\text { consumption at time } t \\
\text { assets at end of stage } s \\
\text { wage in stage } s \\
\text { gross income for stage } s \\
\text { gross earnings for stage } s\end{array}$ & $\begin{aligned} \tau^{r}: & \text { social security tax } \\
\tau^{u}: & \text { unemployment insurance tax } \\
b: & \text { unemployment benefit } \\
& \text { (replacement ratio) } \\
I: & \text { duration of investment }\end{aligned}$ \\
\hline & Gross Earnings & $\begin{array}{l}\text { Gross Income } \\
\text { (earnings + benefits) }\end{array}$ \\
\hline Stage 1 & $E_{1}=w_{1} T_{1}$ & $Y_{1}=E_{1}$ \\
\hline $\begin{array}{r}\text { Stage } 2 \\
\text { (displaced) }\end{array}$ & $E_{2}^{d}=\left(T_{2}-T_{1}-I\right) w_{2}(I)$ & $Y_{2}^{d}=E_{2}+b Y_{1} I$ \\
\hline $\begin{array}{r}\text { Stage 2 } \\
\text { (notdisplaced) }\end{array}$ & $E_{2}^{n}=\left(T_{2}-T_{1}\right) w_{1}$ & $Y_{2}^{n}=E_{2}^{n}$ \\
\hline Stage 3 & $E_{3}=0.0$ & $Y_{3}^{i}=\tau^{r}\left(Y_{1}+Y_{2}^{i}\right)$ \\
\hline
\end{tabular}

All earned income in stages 1 and 2 is subject to tax at a rate $\tau^{r}+\tau^{u}$. Income from unemployment benefit is subject to a tax at rate $\tau^{r}$. 
Table 2: Parameters for Numerical Solution

\begin{tabular}{c|cc}
\hline & & \\
Parameter & Baseline & Alternatives \\
$\gamma$ & 1.5 & \\
$\eta$ & 0.5 & \\
$w_{1}$ & 1.0 & {$[0.25,1.75]$} \\
$T_{1}$ & 1.0 & {$[0.25,1.75]$} \\
$T_{2}$ & 1.0 & {$[0,0.7]$} \\
$T_{3}$ & 1.0 & \\
$b$ & 0.2 & \\
$\tau^{r}$ & $0.05,0.30,0.45$ & \\
\multicolumn{2}{l}{} \\
\hline \multicolumn{2}{l}{ Total length of life remains fixed at 3 units. Variation in age at job loss through } \\
varying $T_{1}$ means age at job loss varies from age 25 through to age 55, if we interpret \\
1 unit of time as being 20 years.
\end{tabular}

Table 3: Liquid Asset Holdings at Job Loss

\begin{tabular}{|c|c|c|}
\hline & $\begin{array}{l}\text { Probit } \\
A>0\end{array}$ & $\begin{array}{c}\text { Regression } \\
\log A \mid A>0\end{array}$ \\
\hline Male & $0.000(.026)$ & $0.005(.092)$ \\
\hline Age & $0.033(.036)$ & $0.374(.118)$ \\
\hline Age 45 & $-0.027(.107)$ & $-0.156(.352)$ \\
\hline High school & $0.109(.025)$ & $0.296(.095)$ \\
\hline University or College & $0.180(.028)$ & $0.391(.108)$ \\
\hline Spouse Present & $\mathbf{0 . 0 8 5}(.028)$ & $0.088(.099)$ \\
\hline Visible Minority & $\mathbf{- 0 . 0 7 2}(.028)$ & $\mathbf{- 0 . 2 3 0}(.103)$ \\
\hline Expected job to end & $-0.015(.023)$ & $0.177(.081)$ \\
\hline Children present & $\mathbf{- 0 . 0 9 6}(.025)$ & $\mathbf{- 0 . 2 6 0}(.09)$ \\
\hline No Pension ${ }^{\dagger}$ & $-0.091(.055)$ & $0.086(.194)$ \\
\hline No Pension $*$ Age $^{\dagger}$ & $-0.030(.044)$ & $-0.056(.153)$ \\
\hline No Pension * Age $45^{\dagger}$ & $0.155(.136)$ & $0.322(.463)$ \\
\hline Number of obserations & 2105 & 1187 \\
\hline
\end{tabular}

Self-reports, 1995 COEP, 1st Interview (3rd quarter after separation from a job). Numbers in bold indicate that the underlying parameter is individually statistically significant at a $10 \%$ level. For probit, estimates are marginal effects (standard error of marginal effect). For the discrete variables, marginal effects are calculated for the change in a dummy variable from zero to one, at the means of all other variables. For the age variables, age is measured in decades and specified as a linear spline with a knot at 45 years of age.

$\dagger$ Test of joint significance of the pension variables: For probit, $\chi^{2}(3)=26.38,($ Prob $>$ $\left.\chi^{2}\right)<0.001$ For regression, test of joint significance of the pension variables: $F(3,1174)=0.30$, Prob $>F=0.828$. 


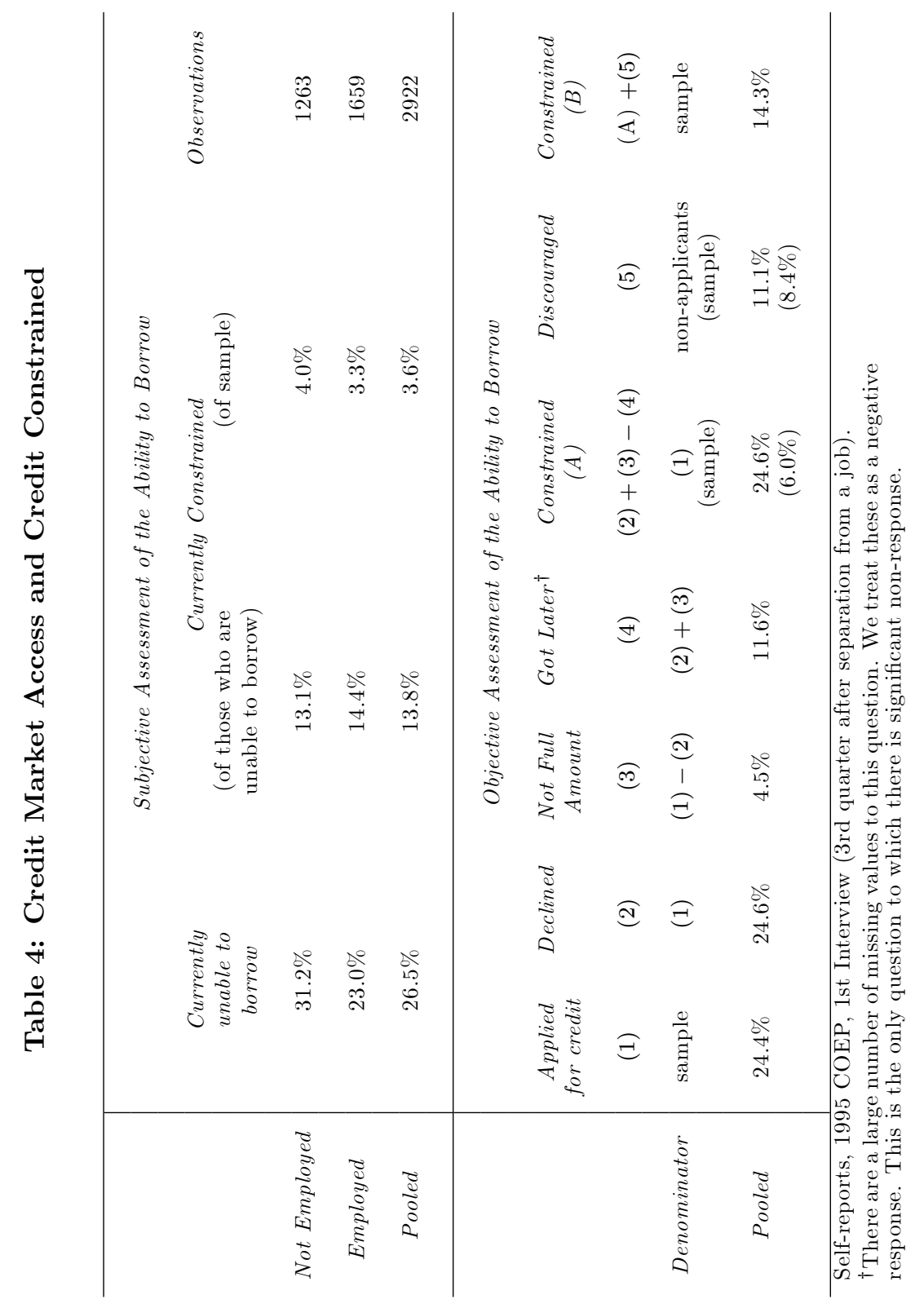




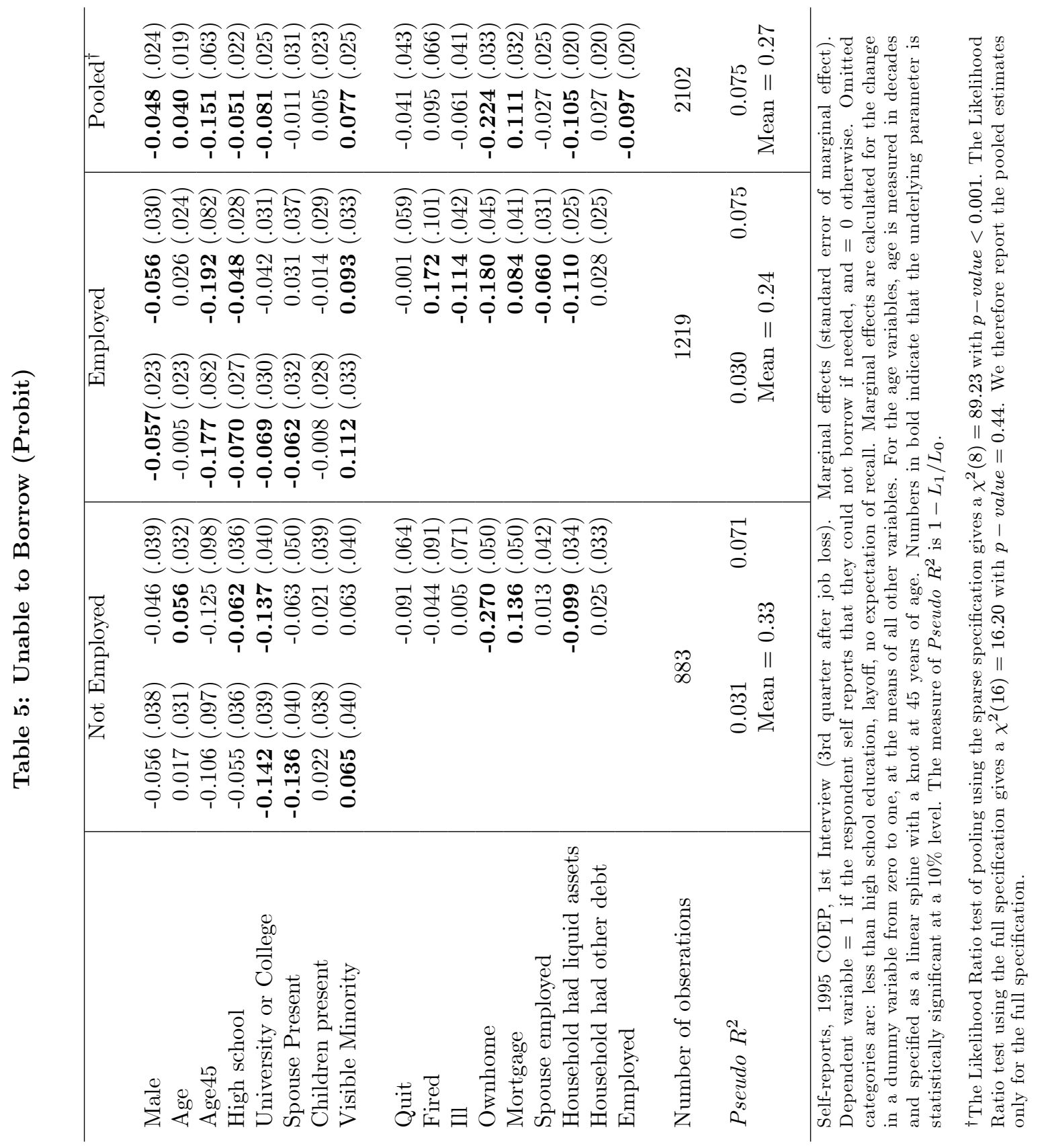




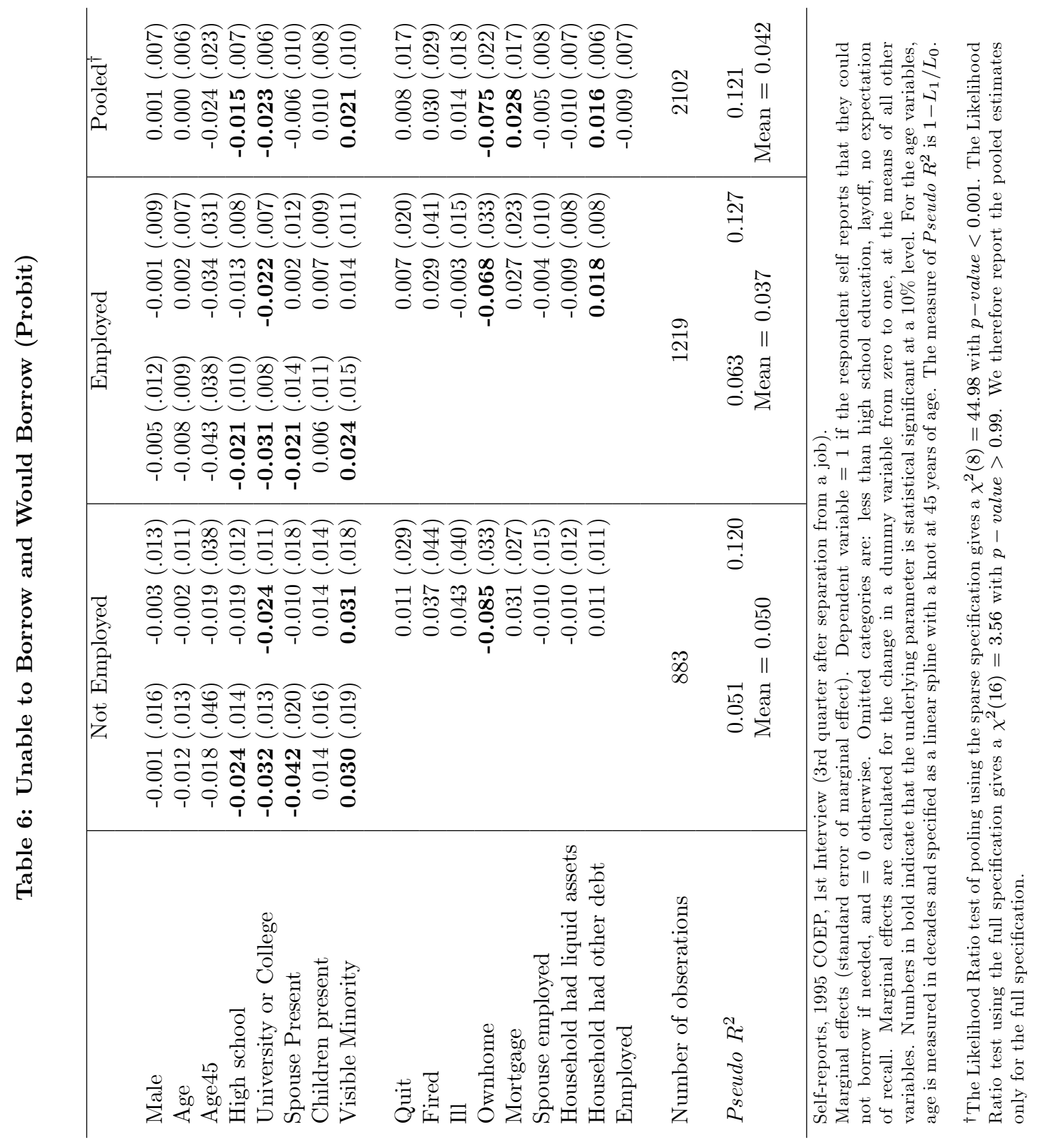


Table 7: Credit Application Rejected or Discouraged (Probit)

\begin{tabular}{|c|c|c|}
\hline Male & $-0.011(.018)$ & $-0.001(.017)$ \\
\hline Age & $\mathbf{- 0 . 0 4 3}(.014)$ & $-0.019(.014)$ \\
\hline Age45 & $-0.038(.052)$ & $-0.033(.050)$ \\
\hline High school & $-0.013(.017)$ & $-0.005(.016)$ \\
\hline University or College & $\mathbf{- 0 . 0 6 4}(.018)$ & $\mathbf{- 0 . 0 5 2}(.018)$ \\
\hline Spouse Present & $\mathbf{- 0 . 0 9 0}(.021)$ & $-0.033(.024)$ \\
\hline Children present & $0.011(.018)$ & $0.017(.017)$ \\
\hline Visible Minority & $0.063(.021)$ & $\mathbf{0 . 0 5 6}(.020)$ \\
\hline Quit & & $0.000(.034)$ \\
\hline Fired & & $0.082(.055)$ \\
\hline Ill & & $0.044(.038)$ \\
\hline Ownhome & & $\mathbf{- 0 . 1 1 4}(.027)$ \\
\hline Mortgage & & $0.020(.025)$ \\
\hline Spouse Employed & & $-0.026(.019)$ \\
\hline Household had liquid assets & & $\mathbf{- 0 . 0 3 3}(.015)$ \\
\hline Household had other debt & & $\mathbf{0 . 0 8 9}(.014)$ \\
\hline Number of obserations & \multicolumn{2}{|c|}{2102} \\
\hline Pseudo $R^{2}$ & 0.042 . & 0.091 . \\
\hline & \multicolumn{2}{|c|}{ Mean $=0.147$} \\
\hline
\end{tabular}

Self-reports, 1995 COEP, 1st Interview (3rd quarter after separation from a job).

Marginal effects (standard error of marginal effect). Dependent variable $=1$ if the respondent self reports that they have had an application for credit declined or that they were discouraged from applying at any time since job loss, and $=0$ otherwise. Omitted categories are: less than high school education, layoff, no expectation of recall. For the age variables, age is measured in decades and specified as a linear spline with a knot at 45 years of age. Marginal effects are calculated for the change in a dummy variable from zero to one, at the means of all other variables. Numbers in bold indicate that the underlying parameter is statistical significant at a $10 \%$ level. The measure of Pseudo $R^{2}$ is $1-L_{1} / L_{0}$. 
Table 8: Kappa Statistics

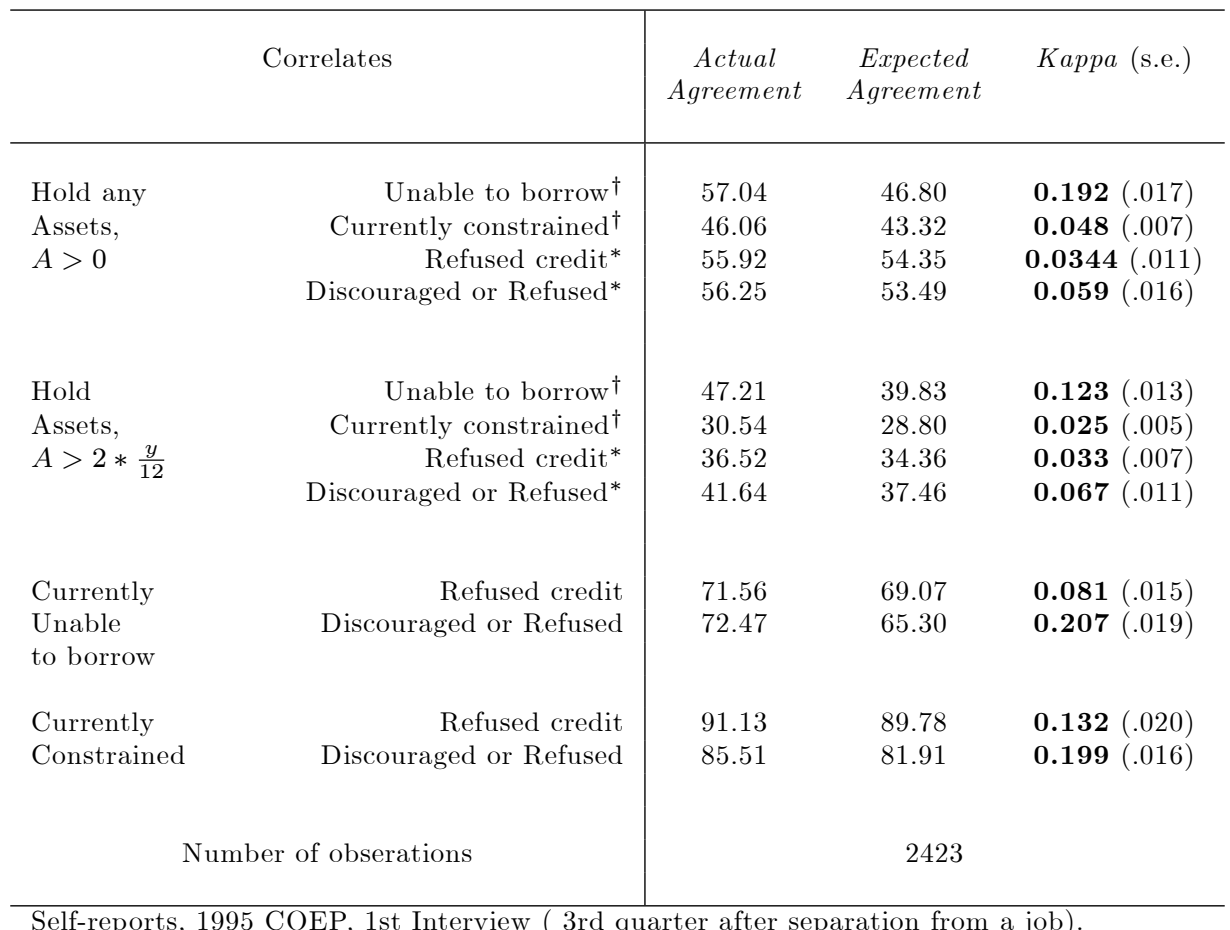

Self-reports, 1995 COEP, 1st Interview ( 3rd quarter after separation from a job).

The column "expected agreement" is the agreement that would be expected to arise by chance. Kappa $=1$ indicates complete agreement, Kappa=0 indicates agreement is the same as by chance, Kappa $<0$ indicates less agreement than expected by chance. All Kappa coefficients reported have p-values less than 0.001 .

$\dagger$ The asset condition refers to asset holdings at interview date which is the same point in time as the credit question.

* The asset condition refers to asset holdings at job loss which is the start of the period covered by this credit question. 


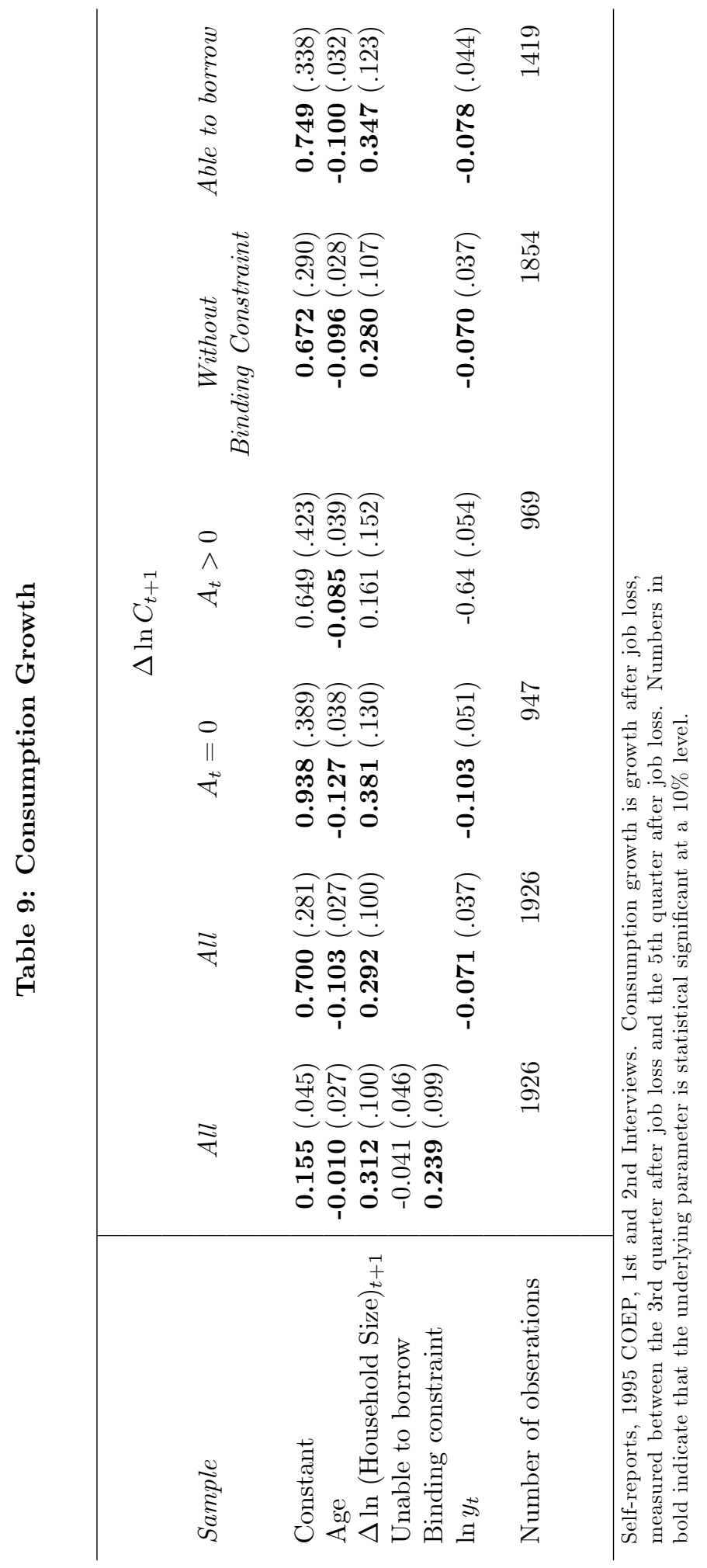




\section{Figures}

Figure 1: Time Path of Earnings

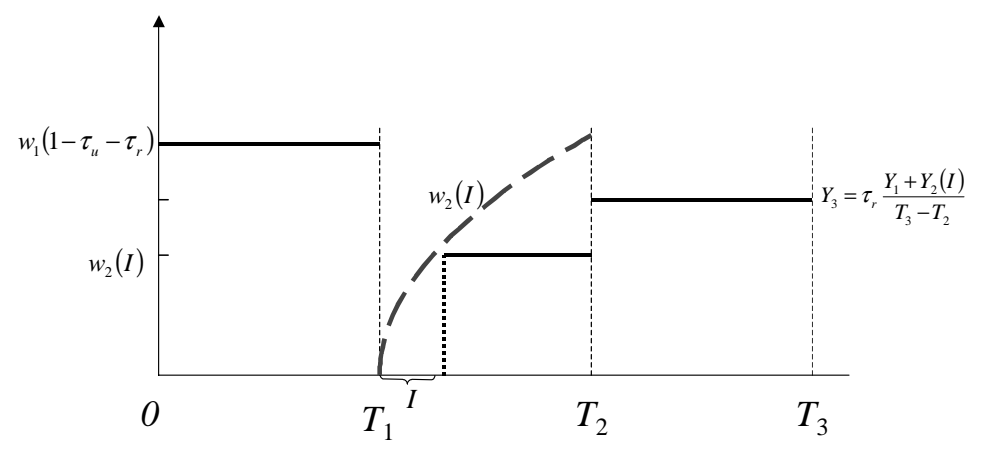


Figure 2: Asset and Consumption Paths

(i) $\tau_{r}=0.45$

Very Impatient
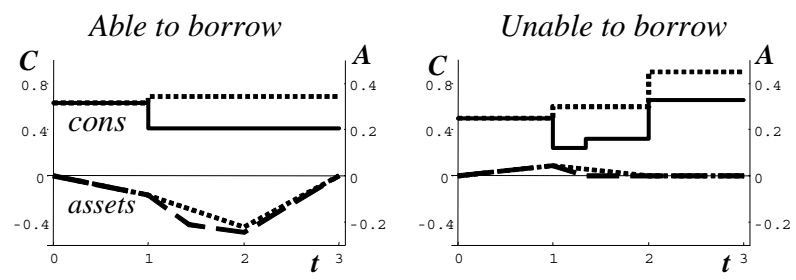

(ii) $\tau_{r}=0.3$

Baseline

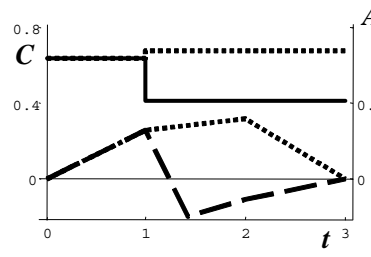

A
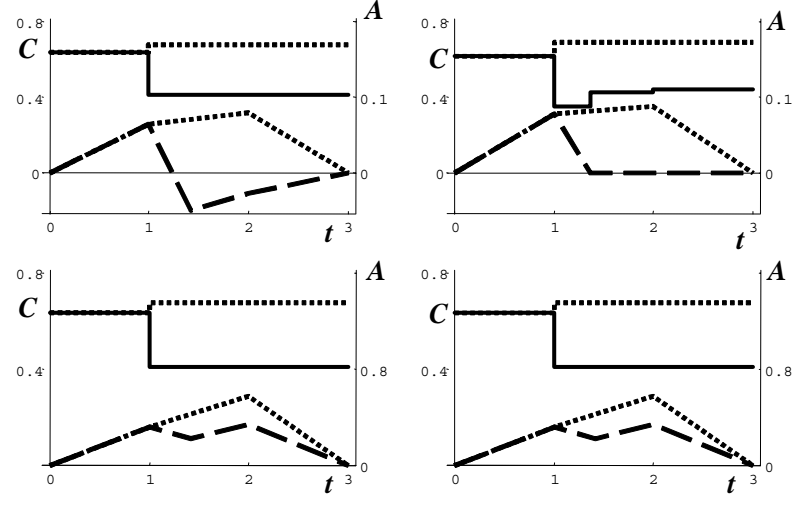

(iii) $\tau_{r}=0.05$

Patient

Consumption if displaced

- Assets if displaced

The left hand column presents consumption and asset paths when able to borrow, the right hand column paths when unable to borrow. The three rows represent different levels of impatience. $C$ is consumption, $A$ is the asset stock at a point in time, $t$ is age, which ranges from 0 to 3 . 
Figure 3: Asset Accumulation by Replacement Rate

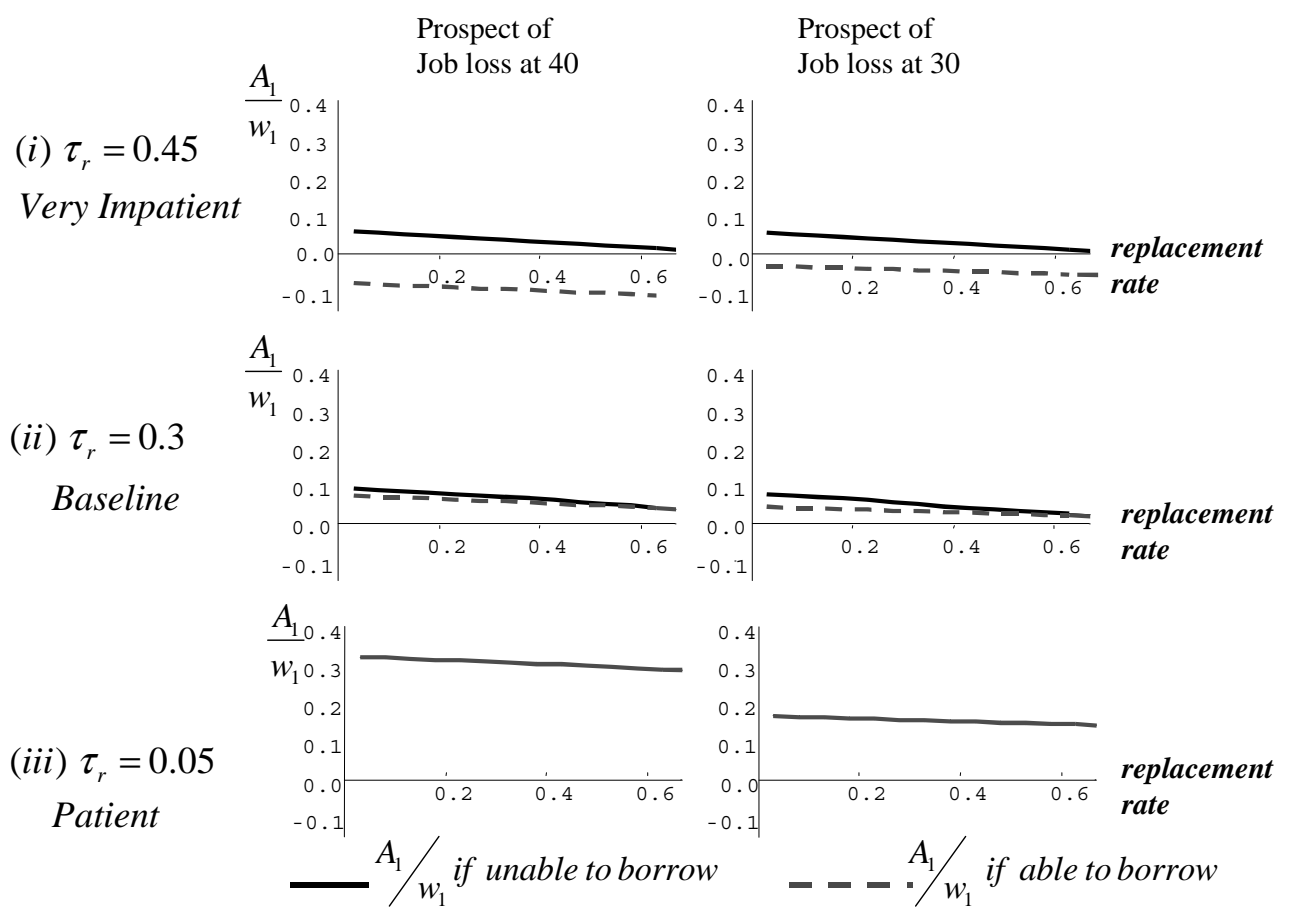

The graphs show asset holdings at job loss, normalised by the wage rate, on the y-axes and the unemployment benefit replacement rate on the x-axes. The left hand column presents the baseline. The right hand column shows the effect of earlier job loss. The wage rate before job loss, $w_{1}$ is the same in both columns. The three rows represent different levels of impatience. The solid lines represent the cases where the agent is unable to borrow, and the lines of dashes represent the cases where the agent can borrow freely. In the third row (showing patient agents) the "uanble to borrow" and "able to borrow" cases coincide. 
Figure 4: Savings Rate by Replacement Rate

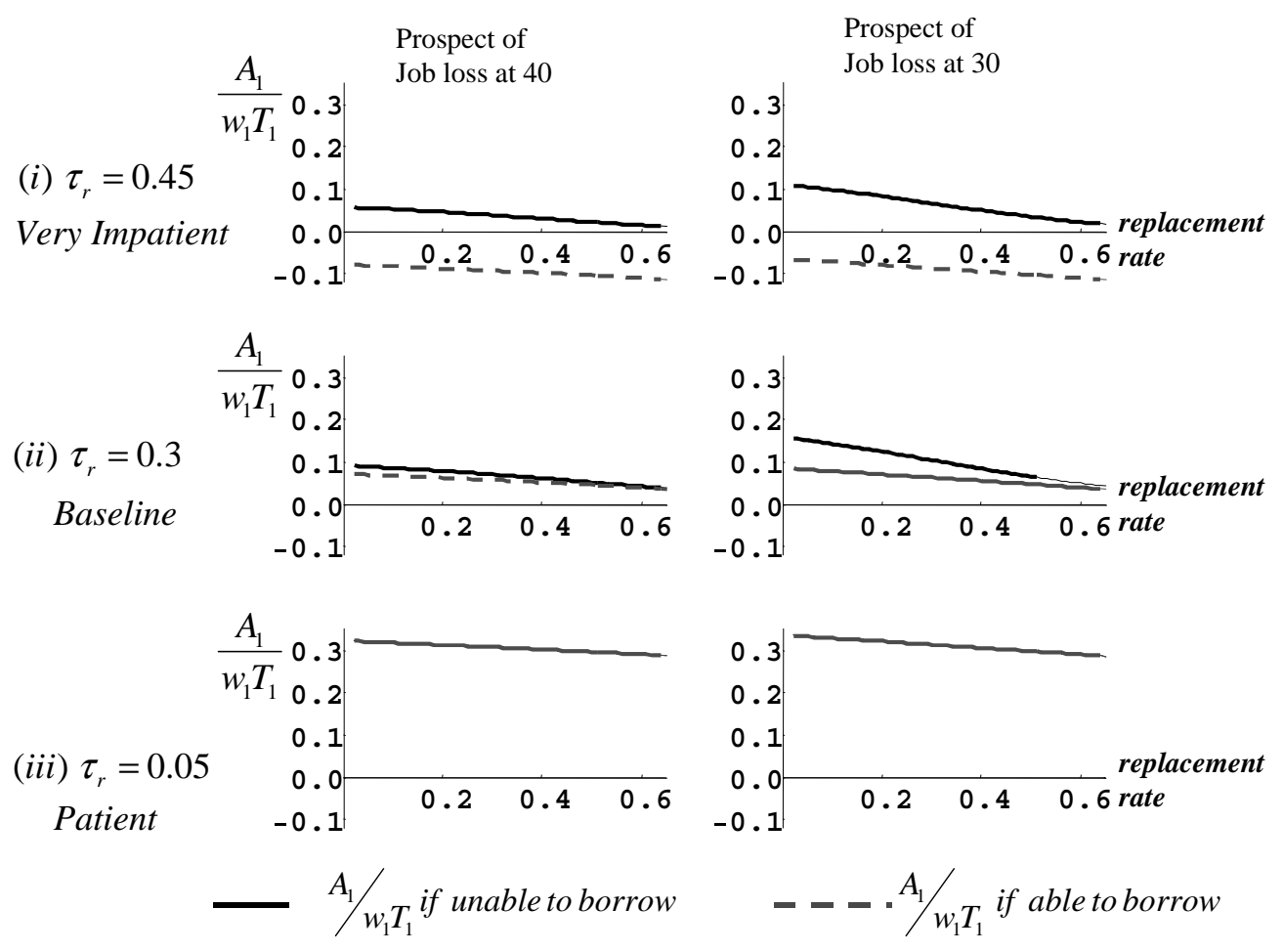

The graphs show the proportion of income saved before job loss on the y-axes and the unemployment benefit replacement rate on the x-axes. The left hand column presents the baseline. The right hand column shows the effect of earlier job loss. Wage rate before job loss, $w_{1}$ is the same in both columns, but $T_{1}$ is smaller when job loss is earlier. The three rows represent different levels of impatience. The solid lines represents the case where the agent is unable to borrow, and the lines of dashes represent the cases where the agent can borrow freely. In the third row (showing patient agents) the "uanble to borrow" and "able to borrow" cases coincide. 
Figure 5: Consumption Loss by Replacement Rate

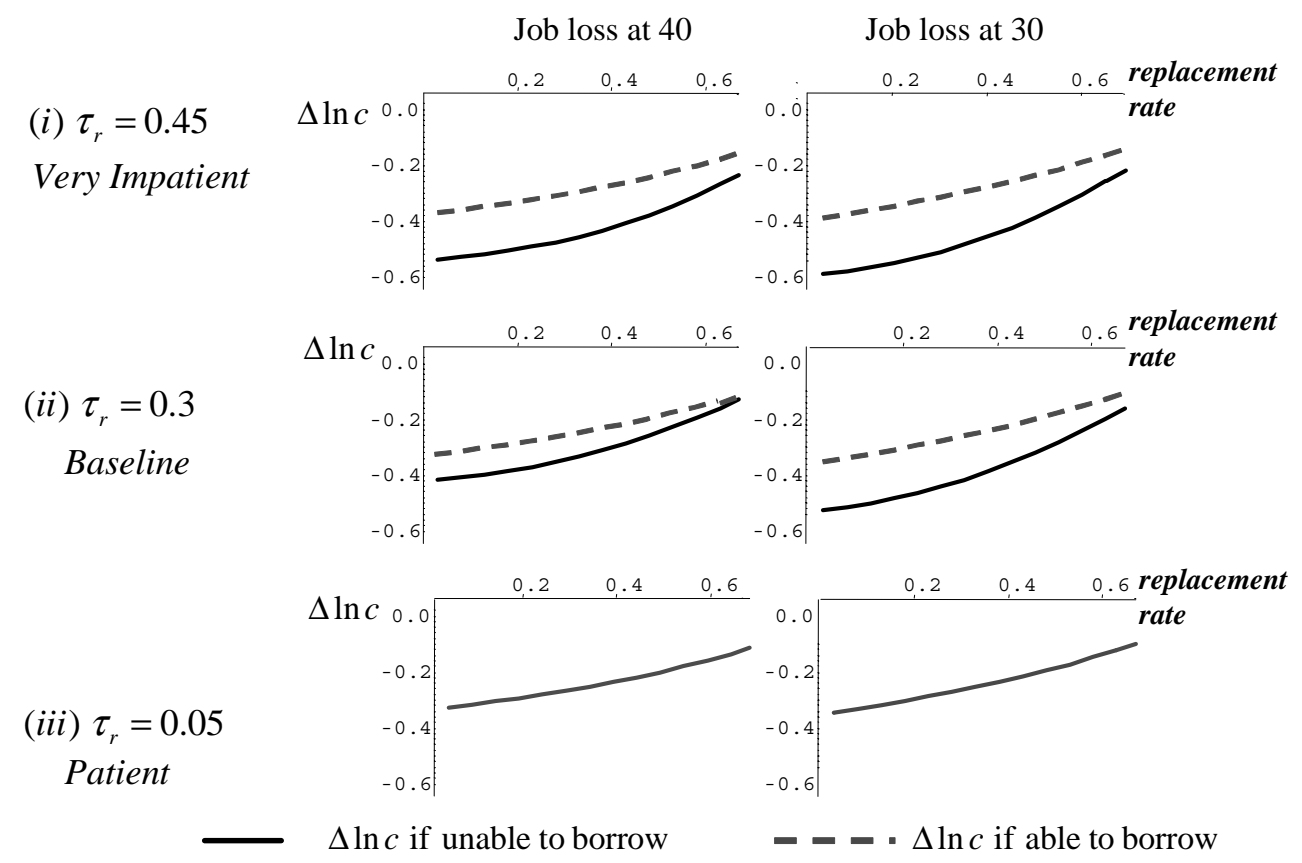

The graphs show the change in consumption at job loss on the y-axes and the unemployment benefit replacement rate on the x-axes. The left hand column presents the baseline. The right hand column shows the effect of earlier job loss. The three rows represent different levels of impatience. The solid lines represents the case where the agent is unable to borrow, and the lines of dashes represent the cases where the agent can borrow freely. In the third row (showing patient agents), the "uanble to borrow" and "able to borrow" cases coincide. 
Figure 6: Investment by Replacement Rate

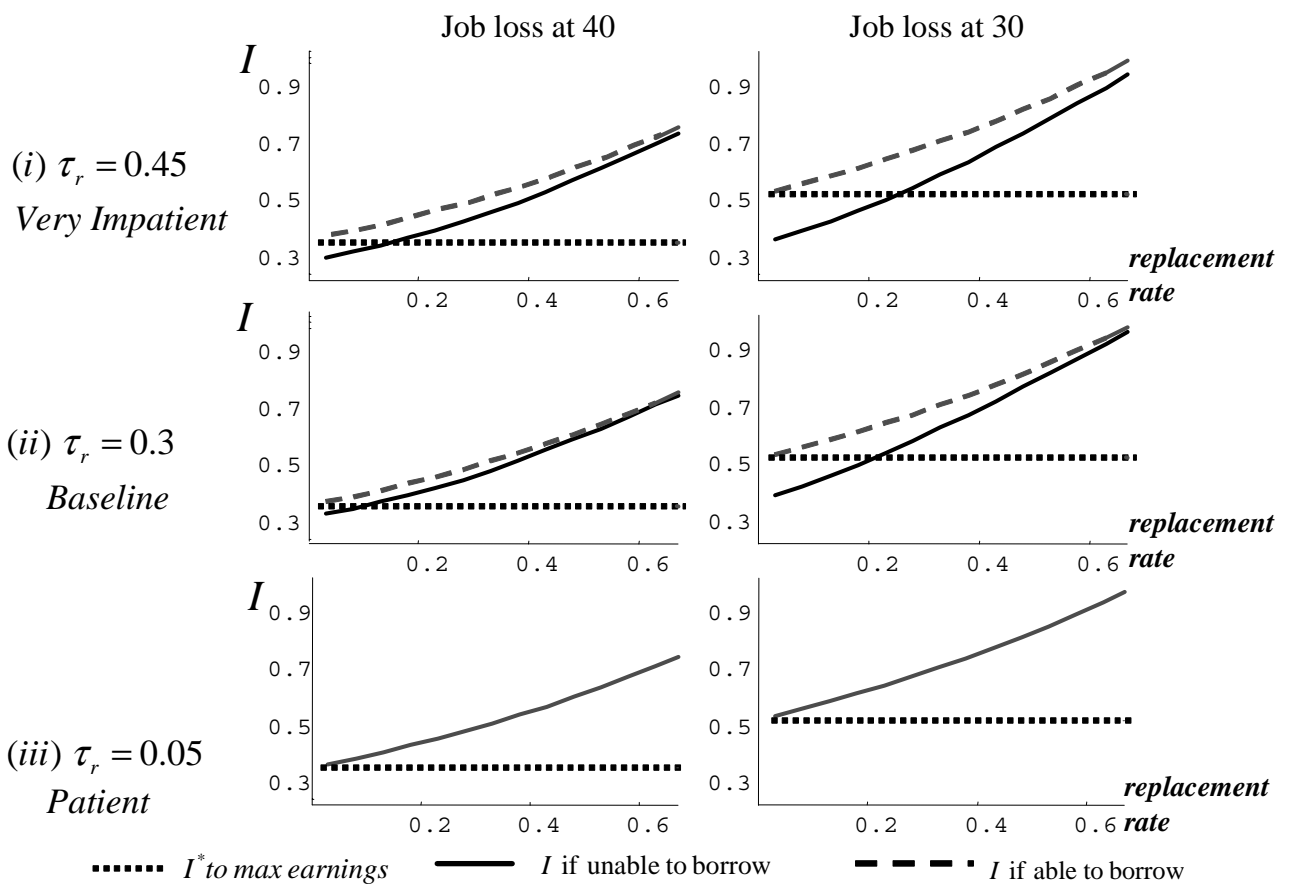

The length of investment (or duration of unemployment) is shown on the y-axes and the unemployment benefit replacement rate on the x-axes. The left hand column presents the baseline. In the baseline, the length of the second stage is 1 , and so the y-axes can be interpreted as the fraction of the period spent unemployed. The right hand column shows the effect of earlier job loss, where the length of the second stage is 1.5. The three rows represent different levels of impatience. The solid lines represent the cases where the agent is unable to borrow, and the lines of long dashes represent the cases where the agent can borrow freely. The optimal level of investment is indicated by the horizontal line of short dashes. 
Figure 7: Optimal Replacement Rates

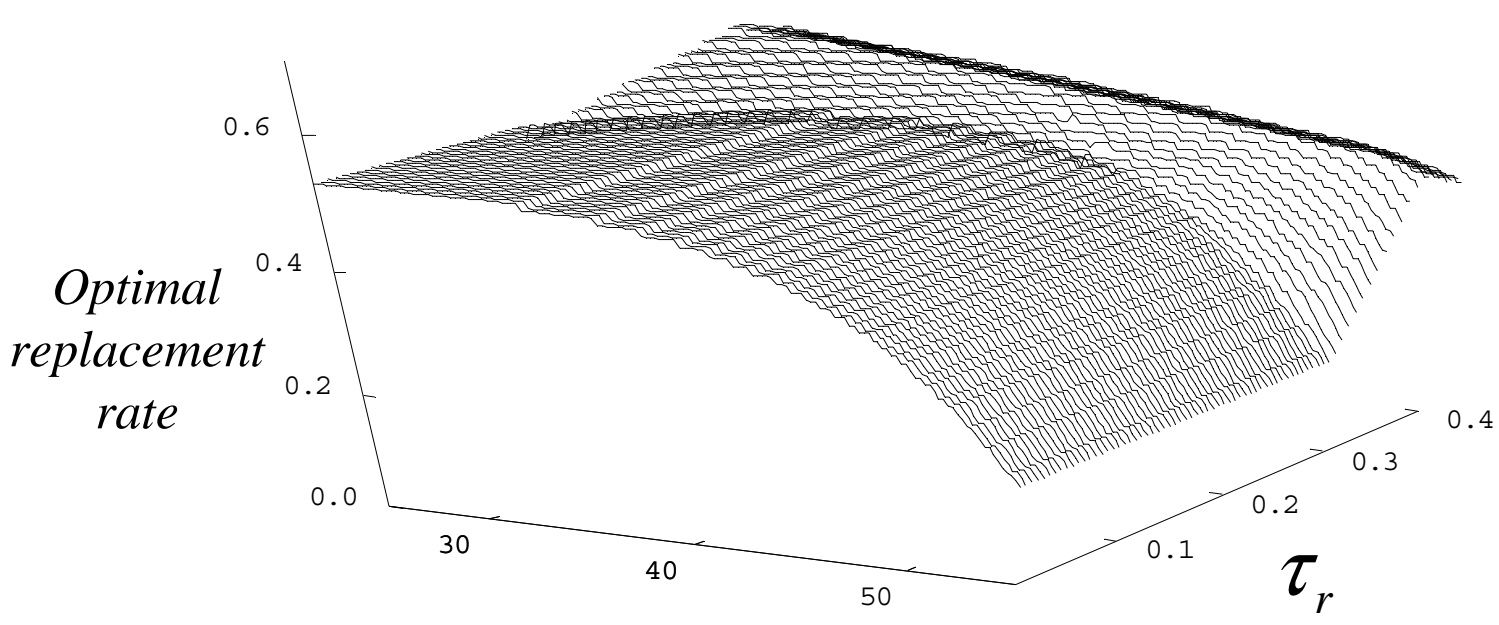

Age at job loss

The optimal benefit ranges from 0.17 to 0.59 . Age at job loss is changed by varying $T_{1}$ : age 25 corresponds to $T_{1}=0.25$ while age 55 corresponds to $T_{1}=1.75$. Age at retirement is set at 60 by $T_{2}$ and remains constant. Fixed parameters: probability of job loss $=0.1, \gamma=1.5$. 
Figure 8: Distribution of Assets and Debt

A. Empirical CDF: Liquid Assets

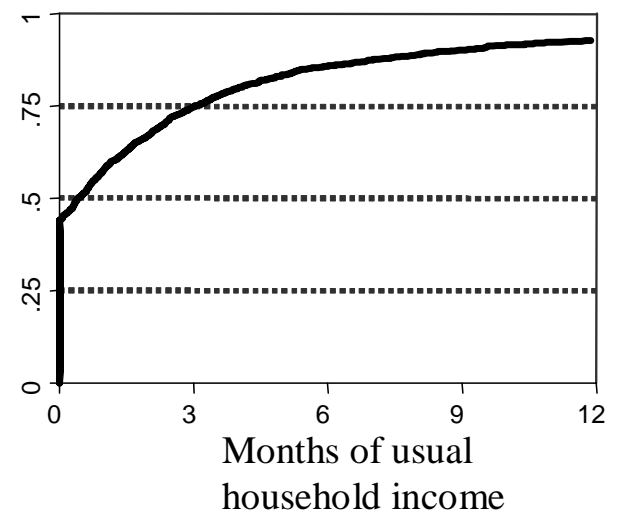

C. Empirical CDF: Net Asset Position

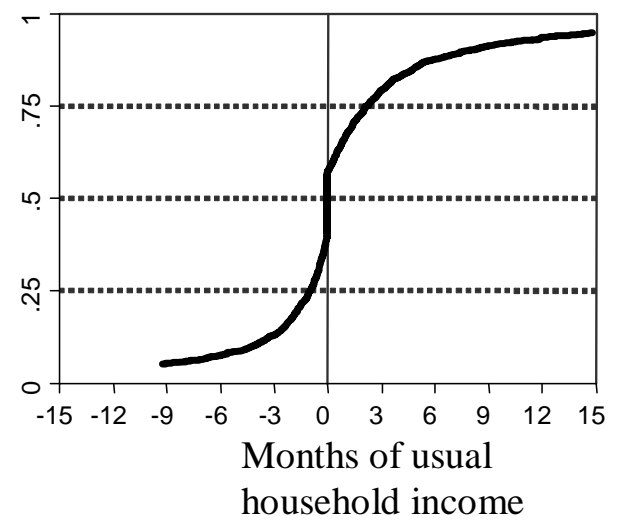

B. Empirical CDF:

Unsecured Debt

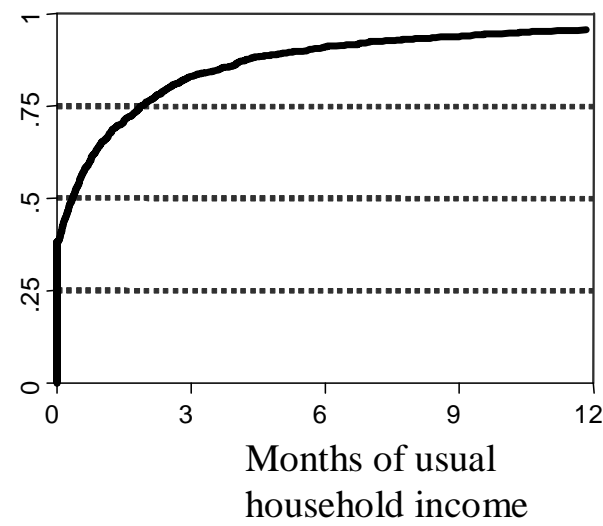

D. Proportion with holdings greater than 1 month of usual income

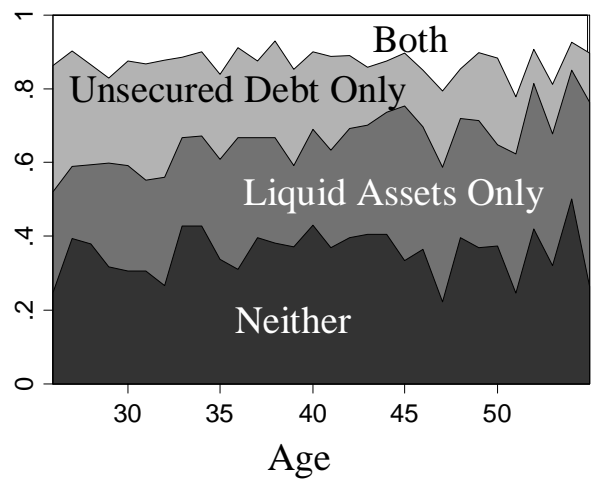

The graphs show the empirical cumulative distributions of liquid assets (top left), unsecured debt (top right) and net position (assets - debt, bottom left). All refer to the time of job loss, and are measured in months of usual household income. The bottom right graph shows, by age, the fraction of the sample who hold at job loss (i) liquid assets amounting to at least one month of usual household income, (ii) unsecured debt of at least one month of usual household income, (iii) both, (iv) neither. 
Figure 9: Asset Holdings, conditional on Pensions and Children
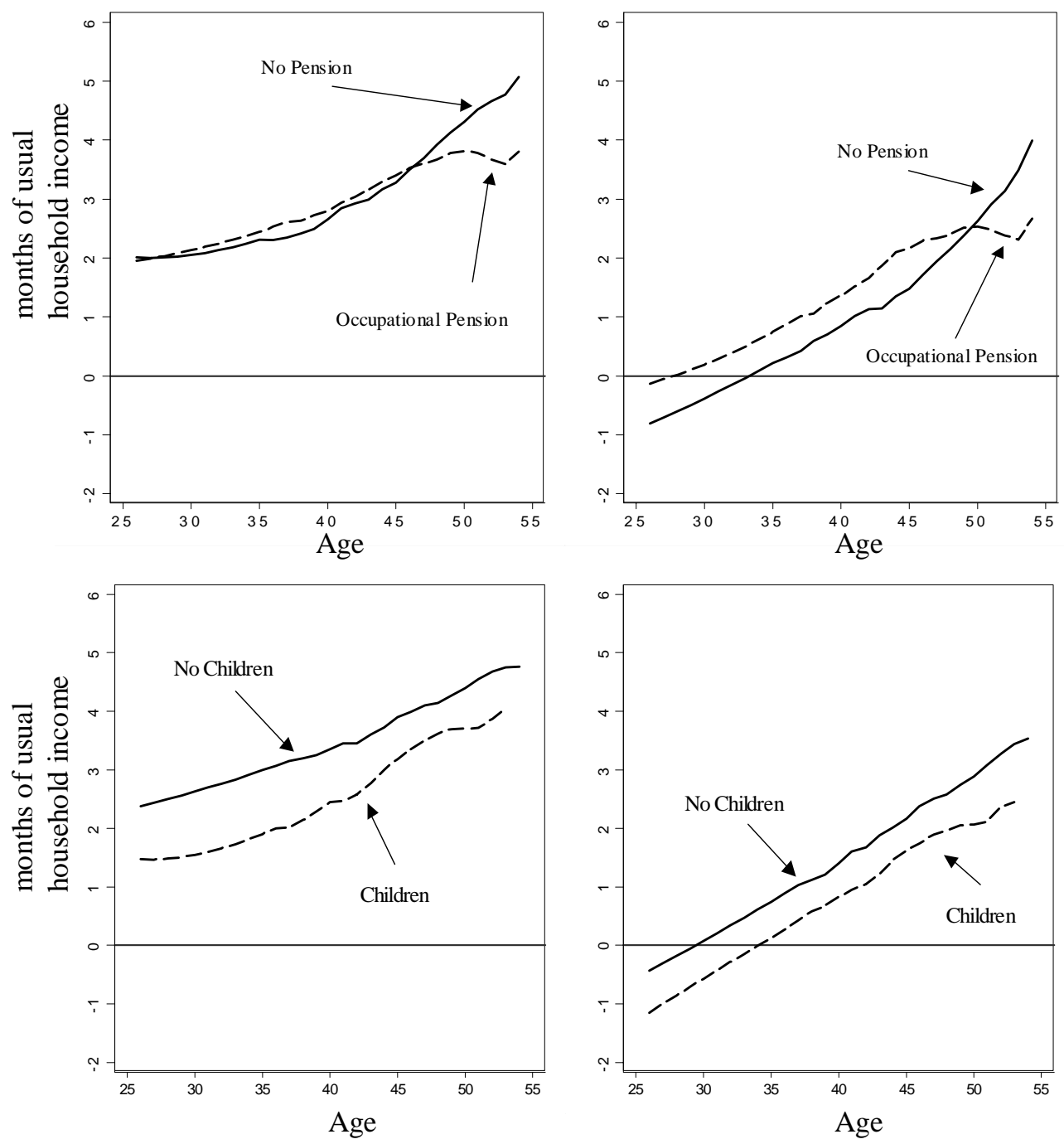

Liquid Assets

Net Position

The graphs show age profiles of financial circumstances for workers losing jobs with and without an employer sponsored pension (top panels) and with and without children present in the home (bottom panels). The left hand panels present liquid assets at job loss (measured in months of usual household income) while the right hand panel present net position (liquid assets - unsecured debt, again measured in months of usual households income). 
Figure 10: Credit Status by Age
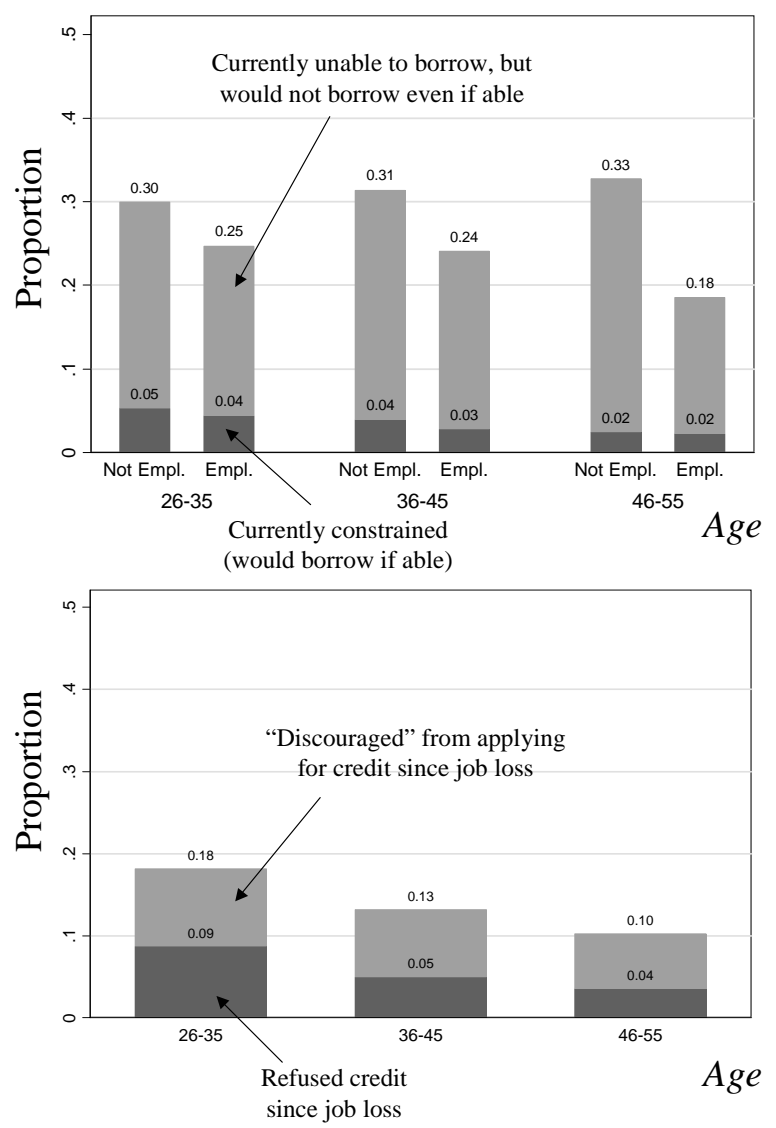

The first graph reports responses to the "subjective" questions on credit status. The second graph reports responses to the "objective" questions on credit status. The subjective questions refer to status at the point in time of the interview and we split the sample by current employment status. The objective questions refer to the whole period since job loss and we do not condition on current employment status. The number located above the lower section on each bar gives the size of the lower section. The number at the top of each bar gives the total for that age group (by employment status for the first graph). 